\title{
Transições no mercado de trabalho brasileiro e os efeitos imediatos da crise econômica dos anos 2010 *
}

\author{
Carlos Eduardo Gomes * \\ Renata Lemos Lima *** \\ Marina Silva da Cunha \\ Marcos Roberto Vasconcelos ${ }^{* * * * *}$
}

\begin{abstract}
Resumo
O presente trabalho analisa as transições e o perfil dos indivíduos no mercado de trabalho das principais regiões metropolitanas brasileiras, considerando os estados de ocupado, desocupado e inativo. As informações básicas são da Pesquisa Mensal de Emprego (PME), para o período compreendido de 2002 até 2015, permitindo verificar o comportamento das transições no mercado de trabalho brasileiro em diferentes fases do ciclo econômico. Os resultados apresentados evidenciam que as chances de transições ao longo desse período são afetadas pelas características individuais, fazendo com que determinados grupos sejam muito mais (menos) desfavorecidos (favorecidos) nas fases recessivas (expansivas) do que outros. As estimativas sugerem que os indivíduos da cor preta, em especial os do sexo feminino, são os mais atingidos em um contexto de crise de emprego, deixando espaço para a discussão da necessidade de se estruturar alguma política pública capaz de atenuar este efeito. Mostra-se ainda que após um longo período, de 2002 a 2014, no qual se observou elevação das chances de os indivíduos permanecerem empregados, o ano de 2015 marcou o agravamento da crise econômica sobre o mercado de trabalho, com queda na transição para ocupação e dilatação do tempo na desocupação.
\end{abstract}

Palavras-chave: Transições no mercado de trabalho; Perfis de transições; Crise econômica.

\section{Abstract}

Transitions in the Brazilian labor market and the immediate effects of the economic crisis of the years 2010

This paper analyzes the transitions and profile of individuals in the labor market in the main Brazilian metropolitan regions, considering the statuses of occupied, unemployed and inactive. The basic information is from the Monthly Employment Survey (PME), from the period 2002 to 2015, making it possible to verify the behavior of the transitions in the Brazilian labor market at different phases of the economic cycle. The results show that the chances of transitions along this cycle are affected by individual characteristics, making certain groups much more (less) disadvantaged (favored) in the recessive (expansive) phases than others. Estimates suggest that blacks, especially females, are the most affected in a context of employment crisis, thus requiring a discussion on the need to structure public policy capable of mitigating this effect. It is also shown that after a long

* Artigo recebido em 11 de novembro de 2016 e aprovado em 8 de junho de 2018. Os autores agradecem aos pareceristas e ao editor da revista Economia e Sociedade pelos valiosos comentários e sugestões de melhorias do artigo.

** Doutor em Economia pelo Programa de Pós-Graduação em Ciências Econômicas (PCE) da Universidade Estadual de Maringá (UEM), Maringá, PR, Brasil. E-mail: cegomes1990@ gmail.com.

*** Doutor em Economia Aplicada do Programa de Pós-Graduação em Economia da Universidade Federal do Rio Grande do Sul (UFRGS), Porto Alegre, RS, Brasil. E-mail: renatalemos87@gmail.com.

**** Professora do Programa de Pós-Graduação em Ciências Econômicas (PCE) da Universidade Estadual de Maringá (UEM), Maringá, PR, Brasil. E-mail: mscunha@uem.br.

${ }^{* * * * *}$ Professor do Departamento de Economia da Universidade Estadual de Maringá (UEM), Maringá, PR, Brasil. Email: mrvasconcelos@uem.br. 
Carlos Eduardo Gomes, Renata Lemos Lima, Marina Silva da Cunha, Marcos Roberto Vasconcelos

period, from 2002 to 2014, in which there was an increase in the chances of individuals remaining employed, 2015 marked the worsening of the economic crisis and the resultant impact on the labor market, with a decrease in the transition to employment and dilation of time in unemployment.

Keywords: Transactions in the Brazilian labor market; Transaction profiles; Economic crisis. JEL J0, J2, J7, E24.

\section{Introdução}

No período recente, estudos mais pormenorizados das características do mercado de trabalho brasileiro ganham relevância. Segundo dados da Pesquisa Nacional por Amostra de Domicílios Contínua, do IBGE, em dezembro de 2016, a taxa de desemprego voltou para a casa dos dois dígitos, $11,5 \%$, e mais de 12 milhões de pessoas estavam desocupadas. Porém, esses efeitos adversos da crise econômica não vêm atingindo de forma homogênea à população. Como mostraremos aqui, a permanência na ocupação ou a chance de encontrar uma nova vaga de trabalho se relacionam com algumas particularidades dos indivíduos. Este fato merece ser destacado, uma vez que alguns estudos apontam ${ }^{1}$ o desemprego como indutor do aumento da pobreza e da desigualdade de renda, e outros que os diferenciais salariais são importantes determinantes desta desigualdade ${ }^{2}$. Ou seja, é na dinâmica do mercado de trabalho que se engendra e se perpetua parte das desigualdades econômicas e sociais brasileiras.

Desde o final da década de 1970, ao examinar as causas do desemprego, a literatura econômica tem dado maior atenção à dinâmica do mercado de trabalho e às transições dos indivíduos nos três estados possíveis neste mercado: ocupado, desocupado e inativo. Conforme Clark e Summers (1979), a taxa de desemprego não seria somente o resultado do número de pessoas por muito tempo na condição de desemprego, mas também dos fluxos de entradas e saídas nesta condição. Em outro trabalho, Clark e Summers (1982) incorporaram na sua análise os demais fluxos, a partir da ocupação e da inatividade, para examinar as transições no mercado de trabalho dos jovens nos Estados Unidos. No Brasil, Bivar (1993) foi a responsável pelo artigo pioneiro na análise das transições no mercado de trabalho, discutindo também a duração esperada do desemprego para homens e mulheres.

O estudo do desemprego passa, então, a exigir análise meticulosa das transições e características do mercado de trabalho, buscando entender tanto os determinantes da oferta quanto os da demanda por trabalho. Se essa demanda é diretamente vinculada ao nível da atividade econômica estimulada pela demanda doméstica e externa por bens e serviços relacionados ao consumo e ao investimento corrente e esperado ${ }^{3}$, a oferta de trabalho reflete em parte os próprios ciclos e fluxos demográficos da população e o perfil do indivíduo em idade ativa, em especial o seu desejo, capacidade e necessidade em estar na condição de ocupado, desocupado e inativo no mercado de trabalho.

(1) Ver Fernandes, Pazello e Felicio (2002) e Ferreira e Barros (1999).

(2) Cunha e Vasconcelos (2012).

(3) Conforme formulado por John Maynard Keynes em sua Teoria da Demanda Efetiva. (Keynes, 1988). 
Ao se analisar o mercado de trabalho brasileiro são encontradas evidências de que desde o início do novo milênio o perfil médio do seu trabalhador tem apresentado mudanças, impulsionado pelo bônus demográfico, aumento da qualificação e da formalização das relações de trabalho e também pelo ciclo econômico expansionista que prevaleceu de 2005 até 2013 na economia, entre outros fatores ${ }^{4}$. Tais mudanças tiveram reflexos diretos no mercado de trabalho, especialmente no perfil e nos fluxos das transições que ocorrem entre ocupação, desocupação e inatividade.

Como mostraremos, nestes primeiros anos do século XXI, a taxa de saída do desemprego em direção à ocupação apresentou, no Brasil, aumento relativo, sugerindo mais desempregados sendo admitidos e menos empregados sendo demitidos. Por outro lado, a parcela de desocupados se reduziu devido à saída de trabalhadores do mercado de trabalho ${ }^{5}$.

Alguns trabalhos já analisaram aspectos das transições no mercado de trabalho brasileiro. Por exemplo, Menezes-Filho e Picchetti (2000), analisando dados apenas referentes à região metropolitana de São Paulo, relativos ao ano de 1997, e incorporando na análise do desemprego características socioeconômicas dos indivíduos, indicaram que a duração esperada do desemprego foi menor para os chefes de família e para os que já tinham trabalhado anteriormente; por outro lado, foi maior para os indivíduos com nível de educação mais elevado, para os idosos e para aqueles que, no emprego anterior, foram demitidos. Por sua vez, Fernandes e Picchetti (1999) analisaram a inatividade e o desemprego, em relação ao comportamento da ocupação, especificamente para o ano de 1995. Oliveira, Scorzafave e Pazello (2009) também tiveram como foco esses estados, porém realizaram uma análise por sexo, examinando os dados referentes apenas ao ano de 2004.

Há, portanto, uma lacuna na análise paramétrica do comportamento das transições no mercado de trabalho brasileiro, uma vez que ainda não foi examinado o comportamento das transições ou fluxos entre as três possíveis situações de emprego, desemprego e inatividade em um período mais extenso de tempo.

No presente artigo buscamos suprir tal lacuna. Considerando o período de março de 2002 a dezembro de 2015, analisamos tanto os três estados no mercado de trabalho (ocupado, desocupado e inativo), quanto os fluxos ou as transições entre os mesmos. Verificamos também se algumas características do perfil dos indivíduos afetam as chances destas

(4) Segundo Chahad e Pozzo (2012), o país passa atualmente por um período de bônus demográfico (com início na década de 1970), o que representa uma janela de oportunidade de desenvolvimento econômico, na qual, com a redução das taxas de natalidade e mortalidade, a parcela da população que depende economicamente da outra parcela é decrescente. Sendo assim, haveria excedentes econômicos que permitiriam o aumento de poupança e, consequentemente, da capacidade de investimento. Como mostram Alves e Cavenaghi (2016), se adotada a definição de população em idade ativa (PIA) como sendo de 15 a 64 anos, a estimativa é que o bônus demográfico brasileiro prosseguirá até o ano de 2024, mas se a definição da PIA for de 15 a 59 anos, este bônus já começará a declinar em 2018.

(5) De acordo com Chahad e Pozzo (2012), houve redução da ocupação entre jovens até 24 anos graças à ação de programas sociais e à saída do mercado de trabalho para qualificação. Sendo assim, é provável que o perfil dos inativos possa ter se transformado, com redução da idade média e aumento da proporção dos estudantes. 
Carlos Eduardo Gomes, Renata Lemos Lima, Marina Silva da Cunha, Marcos Roberto Vasconcelos

transições. Ademais, inferimos o comportamento das transições separadamente de homens e de mulheres no mercado de trabalho metropolitano brasileiro e buscamos verificar os efeitos imediatos da crise econômica brasileira que se agravou a partir de 2014. Para tanto, utilizamos dados da Pesquisa Mensal de Emprego (PME), realizada mensalmente pelo Instituto Brasileiro de Geografia e Estatística (IBGE).

O trabalho está estruturado em quatro seções, além dessa introdução e das considerações finais. Na seção seguinte apresentamos breve revisão de literatura e, na sequência, os procedimentos metodológicos, que se constituem em uma análise não paramétrica, com os cálculos das probabilidades de transição, e uma análise paramétrica, com a estimação do modelo logit multinomial. O exame da evolução das transições no mercado de trabalho metropolitano, com base na análise não paramétrica, é realizado na seção três. Por fim, na quarta seção, os resultados das estimativas do modelo logit multinomial são expostos e discutidos, buscando destacar algumas particularidades dos indivíduos capazes de afetar suas chances de transição no mercado de trabalho brasileiro.

\section{Revisão de literatura}

Os estudos a respeito da dinâmica temporal das transições no mercado de trabalho brasileiro ainda são escassos $\mathrm{E}$ os que trataram o assunto evidenciaram pontos específicos, tais como a relevância do sexo ou da idade do indivíduo ou o tempo na situação de desemprego. Já na literatura internacional são encontrados estudos que analisaram as probabilidades de transição entre os três diferentes estados, considerando aspectos gerais e específicos. Como já apontado na introdução, o trabalho pioneiro foi o de Clark e Summers (1982) com um estudo sobre o desemprego dos jovens nos Estados Unidos para o ano de 1976. Nele, os autores apresentaram duas explicações principais para as causas do desemprego entre os jovens: a primeira seria a alta rotatividade entre os empregos; e, a segunda a falta de oferta de vagas para trabalhadores nesta faixa etária.

Mais recentemente, Ward-Warmedinger e Macchiarelli (2013) analisaram e apontaram diferentes padrões de transições no mercado de trabalho ocorridas nos países da União Europeia no período entre 1998-2008. Os autores concluíram que as probabilidades de transição da inatividade e do desemprego para o emprego eram menores na Zona do Euro e no Leste Europeu quando comparados à Suécia e à Dinamarca. Além disso, a análise das mudanças nas probabilidades de transição ao longo do período mostrou que a probabilidade de se permanecer desempregado por mais de dois períodos diminuiu na Suécia e Dinamarca, enquanto na Zona do Euro e no Leste Europeu esta probabilidade aumentou, indicando um mercado de trabalho mais dinâmico naqueles dois países do que nas demais economias da União Europeia.

Alguns trabalhos examinaram as transições no mercado de trabalho considerando como escopo principal aferir os efeitos específicos de uma política pública ou do sexo e faixa etária do trabalhador. Por exemplo, Bradbury (2014) analisou os efeitos do seguro 
Transições no mercado de trabalho brasileiro e os efeitos imediatos da crise econômica dos anos 2010

desemprego nas transições do mercado de trabalho norte-americano no período entre 2005 e 2013, concluindo que os indivíduos que perdem o emprego tendem a permanecer no mercado de trabalho na condição de desempregado em busca de um emprego até o fim do benefício, mas que, a partir deste ponto, ascende a probabilidade de transitarem para a inatividade. Esta autora encontra evidências de que a política de seguro desemprego nos EUA estimularia os indivíduos a permanecerem mais tempo no mercado de trabalho em busca de trabalho, sem que isso indique menor disposição em aceitar as vagas de emprego disponíveis. Ou seja, o seguro desemprego parece implicar taxas de desemprego mais altas não pelo fato de os indivíduos beneficiados serem mais seletivos às vagas ofertadas, mas sim por manter mais elevada a taxa de participação no mercado de trabalho durante períodos recessivos. Já Peutere et al. (2015) realizaram um estudo sobre a transição da mulher no mercado de trabalho finlandês após o nascimento do primeiro filho, de 1991 até 2005, considerando o emprego formal e temporário. Os autores encontraram que a inserção no mercado de trabalho tende a continuar a mesma após o nascimento do primeiro filho, exceto quando o emprego é temporário, dado que essa condição dificulta o acesso à licença familiar e, ao obrigar a mãe a sair temporariamente do mercado de trabalho, pode apresentar consequências de longo prazo sobre a continuidade do emprego e da divisão do trabalho remunerado e não remunerado na família.

Já o estudo de Stiera et al. (2015) abordou as dificuldades de emprego dos idosos no mercado de trabalho israelense, durante os anos de 2005 a 2010, traçando um perfil de transição dos trabalhadores. Os resultados encontrados sugerem que idosos, tanto homens como mulheres são, de fato, menos propensos a deixar seus empregos. Porém, uma vez fora da força de trabalho, eles enfrentam dificuldades em encontrar um novo emprego, sendo essa dificuldade maior para as mulheres do que para os homens.

Na literatura nacional, conforme já observado, Bivar (1993) foi a responsável pelo artigo pioneiro sobre as transições no mercado de trabalho, utilizando os dados da PME, para os anos de 1983 a 1990, e tendo como foco apenas a condição de desemprego. Utilizando a análise de sobrevivência e dados referentes o ano de 1997, Menezes-Filho e Picchetti (2000) complementaram o trabalho de Bivar (1993), ao buscar os determinantes para a duração no estado de desemprego especificamente para a região metropolitana de São Paulo. Verificaram o chefe de família e os ex-empregados como menos propensos a permanecerem em situação de desocupação, sendo o oposto para os indivíduos idosos e que tinham sido demitidos em sua última ocupação.

Flori (2003), também focando a situação de desemprego, encontrou uma relação inversa entre taxa de desemprego e idade. Para a autora, as altas taxas de desemprego entre os jovens seriam uma decorrência da alta rotatividade destes no mercado de trabalho, e não pela dificuldade em encontrar o primeiro emprego, em linha com a primeira explicação formulada por Clark e Summers (1982). Desta forma, o jovem apresentaria baixa duração no emprego e não uma alta duração no desemprego, o que seria o responsável pelas suas altas taxas de desemprego. Por sua vez, a duração no desemprego foi o foco de alguns trabalhos, tais como 
Carlos Eduardo Gomes, Renata Lemos Lima, Marina Silva da Cunha, Marcos Roberto Vasconcelos

Antigo e Machado (2006) e Menezes e Cunha (2012), que observaram maior sobrevivência na condição de desemprego para mulheres, não-brancos e com maiores níveis de escolaridade.

Já Camargo e Reis (2005) analisaram a assimetria de informação e seus efeitos nos níveis de desemprego entre jovens e trabalhadores semiqualificados. Concluíram que o maior desemprego entre jovens reflete a maior rotatividade deste grupo, talvez decorrente de uma maior assimetria de informação na relação empregador e empregado. Assim, maior incerteza quanto à real produtividade do trabalhador jovem no momento da contratação levaria a maior taxa de demissão dos jovens à medida que a assimetria de informação fosse sendo eliminada. Outro fator citado para o superior desemprego entre os jovens foi o fato de o custo de oportunidade do desemprego ser menor, pois, na maioria das famílias, o jovem não é o principal provedor da renda domiciliar, podendo, então, ser mais seletivo na escolha do trabalho.

Considerando o estado de ocupado como referência, Oliveira, Scorzafave e Pazello (2009) analisaram o perfil dos indivíduos que se encontraram nos estados de inatividade ou desemprego no ano de 2004. Concluíram que o aumento do desemprego verificado naquele ano foi mais forte para as mulheres e que a presença de filhos pequenos não afetou a inatividade masculina, mas impactou consideravelmente a feminina, pois crianças exigiriam maior dedicação de tempo das mães, desincentivando a entrada delas no mercado de trabalho. Com relação ao número de adultos na família, verificaram que quanto maior tal número menor parece ser o custo de oportunidade de um indivíduo ingressar no mercado de trabalho ou de permanecer desempregado. Encontraram também maior incidência de desemprego entre pardos e negros, fruto do processo discriminatório e/ou do efeito de características não observáveis, como a qualidade da educação, e ainda observaram uma relação inversa com a escolaridade, refletindo um maior custo de oportunidade da inatividade quanto maior a educação. Os autores ainda concluíram que a taxa de inatividade é semelhante entre homens e mulheres apenas para a faixa etária de jovens. Para as demais faixas etárias, a participação masculina e feminina no mercado de trabalho apresenta diferenças significativas, sendo a taxa de inatividade entre as mulheres superiores à taxa masculina.

Na próxima seção são apresentados os procedimentos metodológicos que adotamos para estudar as transições no mercado de trabalho metropolitano brasileiro de 2002 a 2015. Assim, considerando a literatura sobre o tema, enquanto para o estudo das transições e fluxos no mercado de trabalho é adotada a abordagem de Clark e Summers (1979 e 1982) já utilizada por Bivar (1993), no modelo empírico para o estudo do perfil dos indivíduos com o modelo logit multinomial, tomamos como base a especificação de Fernandes e Picchetti (1999) e Oliveira, Scorzafave e Pazello (2009), que consideraram respectivamente as PNADs de 1995 e 2004.

Desse modo, o presente trabalho contribui com o debate sobre o tema ao adicionar duas metodologias para análise das transições no mercado de trabalho em longo período de 
Transições no mercado de trabalho brasileiro e os efeitos imediatos da crise econômica dos anos 2010

tempo abrangendo ciclo econômico de expansão e contração. Além disso, avançamos em relação a tais trabalhos, pois ambos analisaram apenas um período de tempo com base na PNAD, enquanto no presente trabalho acompanhamos os indivíduos em dois períodos de tempo e, portanto, incorporamos dinâmica à análise das transições a partir de cada um dos três estados, utilizando as informações longitudinais da PME.

\section{Procedimentos metodológicos}

A base de dados utilizada para a análise das transições no mercado de trabalho foi a Pesquisa Mensal de Emprego (PME), realizada pelo Instituto Brasileiro de Geografia e Estatística (IBGE). Iniciada em 1980, a PME é uma pesquisa de periodicidade mensal, com informações obtidas a partir de uma amostra probabilística de domicílios nas principais Regiões Metropolitanas (RMs) do país: São Paulo, Rio de Janeiro, Belo Horizonte, Recife, Porto Alegre e Salvador.

A pesquisa tem como tema o trabalho e as características demográficas e educacionais dos trabalhadores. Desde o seu início, a PME passou por várias alterações metodológicas, sendo a última em 2002, quando houve uma mudança no questionário de pesquisa. Deste modo, a periodicidade utilizada neste trabalho será mensal e compreenderá o período de março/2002 até dezembro/2015. Consideramos os indivíduos com informações disponíveis com 18 anos ou mais de idade 6 . Vale destacar que o número inicial de observações da amostra foi de 16.339.615 e, após as exclusões dos indivíduos com alguma informação incompleta, o tamanho se reduziu para 9.274.207 observações, quantitativo ainda relevante. Ademais, utilizamos os pesos disponibilizados na PME para obter as estimativas apresentadas no trabalho.

A PME acompanha os mesmos entrevistados ao longo de um período de tempo através de um esquema de rotação de painéis. Cada painel é equivalente a um conjunto de domicílios selecionados sendo dividido em quatro partes que correspondem a uma semana de referência do mês. Através da rotação dos painéis, em cada mês uma das partes da amostra é substituída. Assim, através da rotação dos painéis, a cada mês são mantidos $75 \%$ dos domicílios e entram 25\% de novos domicílios e assim sucessivamente. Além disso, um painel permanece na amostra por quatro meses seguidos, saindo durante os oito meses subsequentes, retornando por um período de mais quatro meses, sendo, então, excluído da pesquisa. Portanto, a cada dois anos $100 \%$ da amostra se repete ${ }^{7}$.

(6) Neste trabalho foram considerados apenas os indivíduos com 18 anos ou mais, buscando contornar as dificuldades de se analisar as transições com os jovens apontadas por Clark e Summers (1979) e já observadas no mercado de trabalho brasileiro por Flori (2003), Camargo e Reis (2005) e Antigo e Machado (2006), segundo os quais, devido à idade escolar dos jovens, sua distinção entre o estado de desemprego e inatividade é mais difícil.

(7) Segundo Ribas e Soares (2008), o acompanhamento de um mesmo indivíduo no mercado de trabalho traria uma maior credibilidade nos dados, de forma a garantir que não houvessem variações causadas pela mudança de informantes. Porém, buscando uma forma de minimizar o cansaço dos informantes, adotou-se um método de rotação de painéis, no qual os entrevistados entram e saem da amostra de acordo com o padrão definido. Desta maneira, a partir dos grupos rotacionais, é possível identificar o indivíduo e acompanhá-lo no período da amostra. 
Seguindo Silva e Pires (2014), o acompanhamento do indivíduo foi feito a partir do emparelhamento, identificando os indivíduos com as variáveis "região metropolitana", "número de controle", "painel", "grupo rotacional", "sexo", "dia de nascimento", "mês de nascimento" e "ano de nascimento". O emparelhamento foi feito a cada dois meses, descartando os indivíduos que não apareceram nos dois meses consecutivos da pesquisa, geralmente indivíduos que estavam no seu primeiro mês de pesquisa. Verificou-se também os domicílios que tinham a presença de crianças de até 5 anos de idade, evidenciando os mesmos com o objetivo de aferir uma possível diferença entre a rotatividade no mercado de trabalho entre homens e mulheres.

Para calcular as probabilidades de transição no mercado de trabalho brasileiro adotamos o procedimento de Clark e Summers (1979 e 1982), também seguido por Bivar (1993). Na construção das séries de transições, partimos da verificação de qual estado o indivíduo se encontrava em dado mês: Ocupado (O), Desocupado (D) ou Inativo (I). No mês seguinte, observamos se o mesmo indivíduo continuava na posição anterior ou mudava de estado. Deste modo, quando os indivíduos mudam ou não de estado nos dois tempos se obtêm as seguintes transições apresentadas na Figura 1. Portanto, OO, DD e II referem-se aos indivíduos que não transitaram entre os dois meses de referência, continuando Ocupado, Desocupado ou Inativo, respectivamente, enquanto DO, IO, OD, ID, OI e DI representam os fluxos de transição dos trabalhadores no período em análise.

Figura 1

Possíveis transições no mercado de trabalho ${ }^{\text {a }}$

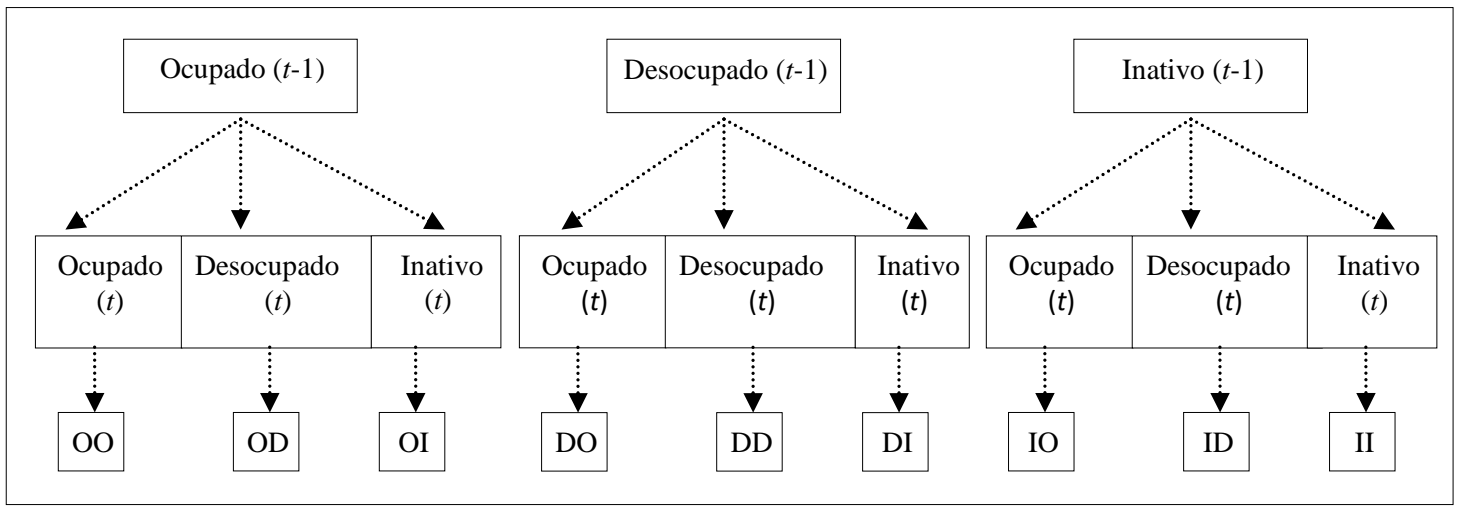

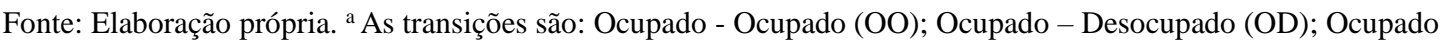
- Inativo (OI); Desocupado - Ocupado (DO); Desocupado - Desocupado (DD); Desocupado - Inativo (DI); Inativo - Ocupado (IO); Inativo - Desocupado (ID); e Inativo - Inativo (II).

As séries construídas seguiram as transições ocorridas mensalmente, iniciando em março/2002 e terminando em dezembro/2015, ou seja, a cada par de meses, evidenciamos as transições ocorridas. O intuito de se utilizar essa metodologia foi comparar e analisar as mudanças ocorridas neste período e possíveis tendências para os próximos anos. 
As categorias ocupado (O), desocupado (D) e inativo (I) correspondem aos estados que um indivíduo pode tomar no mercado de trabalho. Ainda que qualquer estado (ocupação, desocupação e inatividade) se mantenha estável mês a mês, é possível dizer que ocorreram fluxos de entrada e saída de indivíduos desses estados. A partir da construção das séries de transições calculamos as probabilidades mensais de cada transição.

Assim, considerando inicialmente o número de pessoas que estavam ocupadas no mês $t-1$, representado por $X_{t-1}$, e ficaram ocupadas, desocupadas ou inativas no mês $t$, denotado por $X_{t}$, as probabilidades de transição a partir do estado de ocupado foram calculadas para cada mês da seguinte forma:

$$
P\left(X_{t} \mid X_{t-1}\right)=\frac{X_{t}}{X_{t-1}}
$$

Da mesma forma, as transições mensais a partir do estado de desocupado e inativo também foram calculadas seguindo a equação (1). As probabilidades de transição do estado anterior, $k$, para o estado atual $j$, possuem as seguintes propriedades:

$$
\begin{gathered}
0<p_{j k}<1 \\
\sum_{j} p_{j k}=1
\end{gathered}
$$

Assim, as probabilidades são sempre positivas e menores que um, sendo que o somatório de todas as possibilidades de transição a partir de um dado estado é igual a um. Para o cálculo das probabilidades anualizadas $\left(p^{a n o}\right)$, as probabilidades mensais foram ponderadas pelas estimativas do estoque de indivíduos no estado inicial $\left(E_{k}\right)$ :

$$
p_{j k}^{a n o}=\frac{\sum_{t=1}^{12} E_{k} \times p_{j k}}{\sum_{t=1}^{12} E_{k}}
$$

Buscando traçar um perfil dos indivíduos em cada estado e/ou transição, foram estimadas regressões utilizando o modelo logit multinomial, tendo como variável dependente uma variável discreta com mais de duas categorias. Conforme Greene (2012), a estrutura geral deste modelo pode ser apresentada como:

$$
\operatorname{Prob}\left(Y_{i}=j \mid \mathbf{w}_{i}\right)=\frac{\exp \left(\mathbf{w}_{i}^{\prime} \boldsymbol{\alpha}_{j}\right)}{\sum_{j=0}^{J} \exp \left(\mathbf{w}_{i}^{\prime} \boldsymbol{\alpha}_{j}\right)} \quad j=0, \ldots, J ; \quad i=1, \ldots, n .
$$

em que $i$ denota o indivíduo, $j$ denota os estados; $\mathbf{w}_{i}$ representa um vetor com as variáveis de controle para o indivíduo $i$ e $p_{i j}$ denota a probabilidade do indivíduo $i$ estar no estado $j$, sendo que neste trabalho $J$ será igual a dois para cada modelo estimado - sendo no total de três - em que são consideradas todas as possíveis transições a partir de cada estado e como 
Carlos Eduardo Gomes, Renata Lemos Lima, Marina Silva da Cunha, Marcos Roberto Vasconcelos

referência o indivíduo que permaneceu no mesmo estado no mês seguinte. Assim, são estimadas regressões para os ocupados, desocupados e inativos. Conforme observa Greene (2012), como as probabilidades somam um, somente $J$ vetores precisam ser estimados para se obter as $J+1$ probabilidades.

Entre os diversos testes propostos para verificar a propriedade de Independência das Alternativas Irrelevantes (IIA $)^{8}$, indicativa de que a inclusão ou exclusão de categorias não irá afetar os resultados das estimativas em modelos logit multinomiais, optamos por utilizar aqui o de Small e Hsiao (1985), pois, conforme Cheng e Long (2007), é considerado robusto para grandes amostras, tal como a do presente trabalho.

As estimativas são apresentadas em razão de chances (odds ratio), dada por $p_{i j} / p_{i 0}$, que indica as chances de se estar no estado $j$ em relação ao estado de referência $j=$ 0. Conforme Cameron e Trivedi (2005), o logaritmo natural da razão de chances, $\ln \left[p_{i j} / p_{i 0}\right]$, é linear com os regressores e o modelo assume a forma de risco relativo. Assim, quando as estimativas dos coeficientes têm valor maior que um, as chances de estar no estado $j$ são maiores do que no estado de referência e, quando é menor que um, as chances são menores do que no estado de referência. Portanto, para cada variável de controle se obtém as chances de o indivíduo transitar do estado inicial para o final, sendo aqui consideradas como estado de referência as chances de permanecer no mesmo estado como ocupado, desocupado ou inativo.

Com relação ao vetor de variáveis de controle, estão incluídas a idade e a idade ao quadrado, para captar a relação não linear entre idade e a condição no mercado de trabalho, que se altera com o ciclo de vida. Para estimar o efeito da educação são utilizadas quatro variáveis binárias de acordo com os anos de escolaridade, de 1 a 3 anos de estudo, de 4 a 7 anos de estudo, de 8 a 10 anos de estudo e com 11 anos ou mais, sendo a categoria de referência aqueles sem instrução ou com menos de 1 ano de estudo. São incluídas duas variáveis binárias para aferir diferenças decorrentes da cor/raça do indivíduo, para pardos e negros.

Inserimos ainda uma variável binária com o objetivo de identificar os domicílios que possuíam filhos de até cinco anos de idade. Incluímos também variáveis binárias de controle para a sazonalidade mensal, em que janeiro foi tomado como base, para as mudanças no ambiente econômico, com variáveis binárias para cada ano, em que o ano de 2002 foi considerado como referência, e para as diferenças regionais, com binárias para as regiões metropolitanas, em que se omitiu a Região Metropolitana de Salvador.

Conforme já observado, a especificação adotada teve como base as utilizadas em Fernandes e Picchetti (1999) e Oliveira, Scorzafave e Pazello (2009). Porém, avançamos em relação a tais trabalhos, pois ambos analisaram apenas um determinado momento no tempo, em que o primeiro estimou um modelo logit multinomial, com três categorias (ocupados,

(8) Em inglês Independence of Irrelevant Alternatives (IIA). 
Transições no mercado de trabalho brasileiro e os efeitos imediatos da crise econômica dos anos 2010

desocupados e inativos) com base em dados referentes a setembro de 1995, e o segundo estimou o modelo separadamente para homens e mulheres a partir de informações da PNAD de 2004, enquanto no presente trabalho acompanhamos as transições mensais dos indivíduos, conforme descrito na Figura 1, a partir de cada um dos três estados, do mês $t-1$ para o mês $t$, ao longo do período de março de 2002 até dezembro de 2015.

Assim, estimamos três modelos para cada sexo'. O primeiro para aqueles que estavam ocupados em $t-1$ e permaneceram ocupados em $t(\mathrm{OO})$, ou transitaram para o desemprego (OD) ou para a inatividade (OI). O segundo para aqueles que estavam desocupados em $t-1$ e permaneceram desocupados em $t$ (DD) ou transitaram para a ocupação (DO) ou para a inatividade (DI). Por sua vez, o terceiro para aqueles que estavam inativos em $t-1$ e permaneceram inativos em $t$ (II), ou que transitaram para a ocupação (IO) ou para o desemprego (ID). Ademais, foram estimadas duas especificações: a primeira (Especificação 1) com as características sócio-demográficas; e a segunda (Especificação 2) incluindo controles para sazonalidade mensal, ciclo anual e região, com a utilização de variáveis binárias. Como expusemos na introdução, os resultados destes modelos são apresentados e discutidos na seção 4, mas antes, na próxima seção, examinamos o comportamento das transições no mercado de trabalho ao longo do período 2002 a 2015.

\section{Evolução das transições no mercado de trabalho brasileiro}

A partir das informações da Pesquisa Mensal do Emprego, conseguimos examinar a composição do mercado de trabalho metropolitano brasileiro, segundo a condição de ocupação e de sexo, conforme sintetizado na Tabela 1. Considerando os dois extremos do período analisado, os anos de 2002 e 2015, foram observados aumentos da ocupação e da inatividade em detrimento da desocupação. Porém essa tendência não se mostrou homogênea ao longo de todo o período. De fato, a parcela da população estimada em situação de inatividade ficou em patamar inferior ao do primeiro ano analisado de 2003 a 2013, quando passa a apresentar trajetória ascendente. Da mesma forma, a partir de 2013 se observa redução na ocupação, enquanto a desocupação salta de 2,8\%, em 2014, para 4,0\% da população estimada, no último ano da série. Todavia, embora a elevação da parcela de indivíduos desocupados de um ano para outro seja expressiva, o percentual de 4,0\% ainda se mostrava abaixo dos patamares do começo do período.

Ao se segmentar a série por sexo, verificamos que homens e mulheres ampliaram o percentual de ocupação até 2012, quando a tendência se reverte e passa a ser decrescente nos três últimos anos. Em relação à inatividade, observamos diferença de trajetória entre homens e mulheres, sendo que os primeiros apresentam tendência de aumento da inatividade enquanto as segundas de decréscimo. Isso está alinhado ao observado por Camarano e Kanso

(9) Vale ressaltar que foi realizado o Teste da Razão de Verossimilhança (LR) com o objetivo de verificar se existia diferença significativa entre os parâmetros estimados para homens e mulheres, justificando a estimação em separado, ou se a regressão em conjunto seria a mais indicada. O resultado do teste confirmou que há diferenças significativas nas estimações para homens e mulheres e, por isso, a estimação foi realizada de forma separada para cada sexo. 
(2012), que, usando dados dos Censos Demográficos de 2000 e 2010 e das PNADs de 2001 e 2011, encontraram aumento do percentual de jovens, definidos como indivíduos com faixa etária entre 15 e 29 anos, do sexo masculino, que não trabalhavam nem estudavam em contraposição à queda na proporção de mulheres jovens nesta mesma situação. No entanto, a partir de 2013, os percentuais de homens e mulheres em condição de inatividade passam a apresentar forte trajetória de alta, o que pode estar relacionado à queda na renda domiciliar e ao impacto disso para a situação dos jovens, conforme apontado por Camarano e Kanso (2012). Notamos também a tendência de aumento da participação feminina no mercado de trabalho ao longo do período, indicando manutenção da tendência observada por Scorzafave e Menezes-Filho (2001), que analisaram a participação das mulheres no mercado de trabalho brasileiro, entre os anos de 1982 a 1997, e verificaram um aumento desta participação em contraponto à estagnação ocorrida para os homens.

Entre os principais determinantes desse aumento da presença feminina no mercado de trabalho pode estar a diminuição da proporção de mulheres com menor nível de escolaridade na população e o aumento na participação das mulheres casadas e idosas. Scorzafave e Menezes-Filho (2001) encontraram uma possível relação entre os movimentos da inatividade e do desemprego, principalmente para as mulheres, na medida em que o maior ingresso dessas no mercado de trabalho não fosse acompanhado da criação de postos de trabalho, fazendo com que o desemprego feminino aumentasse e a inatividade diminuísse.

Tabela 1

Composição do mercado de trabalho metropolitano brasileiro, 2002-2015

\begin{tabular}{|c|c|c|c|c|c|c|c|c|c|c|c|c|c|c|}
\hline Variável & 2002 & 2003 & 2004 & 2005 & 2006 & 2007 & 2008 & 2009 & 2010 & 2011 & 2012 & 2013 & 2014 & 2015 \\
\hline \multicolumn{15}{|c|}{ Posição na ocupação } \\
\hline Ocupado & 57,0 & 58,1 & 58,5 & 58,9 & 59,1 & 59,5 & 60,4 & 60,0 & 61,1 & 61,4 & 61,7 & 61,2 & 60,0 & 58,1 \\
\hline Desocupado & 6,9 & 7,6 & 7,0 & 6,0 & 6,1 & 5,7 & 4,9 & 5,0 & 4,2 & 3,7 & 3,4 & 3,2 & 2,8 & 4,0 \\
\hline Inativo & 36,1 & 34,4 & 34,5 & 35,1 & 34,8 & 34,7 & 34,7 & 35,0 & 34,7 & 35,0 & 35,0 & 35,6 & 37,2 & 37,9 \\
\hline \multicolumn{15}{|c|}{ Composição por sexo } \\
\hline Homens & 46,4 & 46,3 & 46,2 & 46,1 & 46,2 & 46,1 & 45,8 & 45,8 & 45,6 & 45,6 & 45,6 & 45,4 & 45,2 & 45,2 \\
\hline Mulheres & 53,6 & 53,7 & 53,8 & 53,9 & 53,8 & 53,9 & 54,2 & 54,2 & 54,4 & 54,4 & 54,4 & 54,6 & 54,8 & 54,8 \\
\hline \multicolumn{15}{|l|}{ Homens } \\
\hline Ocupado & 70,5 & 71,7 & 71,7 & 71,9 & 71,7 & 72,0 & 73,0 & 72,0 & 73,3 & 73,5 & 73,5 & 72,7 & 71,4 & 69,0 \\
\hline Desocupado & 7,1 & 7,4 & 6,6 & 5,6 & 5,9 & 5,4 & 4,4 & 4,7 & 3,8 & 3,3 & 3,1 & 3,1 & 2,8 & 4,2 \\
\hline Inativo & 22,4 & 21,0 & 21,7 & 22,4 & 22,3 & 22,6 & 22,6 & 23,2 & 22,9 & 23,1 & 23,4 & 24,2 & 25,8 & 26,8 \\
\hline \multicolumn{15}{|l|}{ Mulheres } \\
\hline Ocupado & 45,2 & 46,4 & 47,1 & 47,7 & 48,2 & 48,8 & 49,8 & 49,8 & 50,9 & 51,1 & 51,8 & 51,5 & 50,5 & 49,0 \\
\hline Desocupado & 6,8 & 7,7 & 7,4 & 6,4 & 6,3 & 6,1 & 5,2 & 5,2 & 4,5 & 3,9 & 3,6 & 3,4 & 2,9 & 3,9 \\
\hline Inativo & 48,0 & 45,9 & 45,5 & 45,9 & 45,5 & 45,1 & 45,0 & 45,0 & 44,7 & 44,9 & 44,7 & 45,1 & 46,6 & 47,1 \\
\hline
\end{tabular}

Fonte: Elaboração própria a partir de informações da PME. 
A evolução das transições no mercado de trabalho metropolitano brasileiro, de 2002 até 2015, pode ser observada nas Figuras 2a, 2b e 2c. Lembramos que as transições são os movimentos que o indivíduo realizou naquele período a partir do seu estado em $t-1$. Por exemplo, o caso das transições dos ocupados (Figura 2a) indicam os fluxos dos indivíduos que estavam ocupados no período $t-1$ e transitaram para a desocupação ou a inatividade no período $t$. $\mathrm{O}$ mesmo raciocínio deve ser estendido às transições a partir do estado de desocupado ou de inativo, nas Figuras $2 \mathrm{~b}$ e $2 \mathrm{c}$. Há também os indivíduos que permanecem no estado inicial, os ocupados (OO), desocupados (DD) e inativos (II), indicados nos eixos da direita.

Como esperado, o comportamento das transições é impactado por efeitos sazonais, uma vez que nos períodos antecedentes às festas de final de ano ou a datas como Dia das Mães há evidente aumento da probabilidade de se manter ocupado e as probabilidades do indivíduo ir para o desemprego ou inatividade caem. Por outro lado, destaca-se também a redução na probabilidade de ocupação de dezembro para janeiro de cada ano, especialmente entre os anos de 2002 e $2003^{10}$. Ademais, pode-se verificar ainda na Figura 2 que a soma dos três estados é igual a 1, conforme a Equação (3).

$\mathrm{Na}$ Figura 2a podem ser observadas as probabilidades das transições a partir da ocupação, ou seja, dos indivíduos que no mês de referência se encontravam ocupados e que no período seguinte transitaram para desocupados (OD) ou inativos (OI), além daqueles que permaneceram ocupados (OO). Deste modo, é possível verificar, de maneira geral, o aumento da probabilidade de indivíduos que não transitaram, ou seja, que estavam ocupados em $t-1 \mathrm{e}$ continuaram ocupados em $t$ ao longo do período analisado. Essa elevação é mais evidente até o ano de 2013, quando a economia brasileira ainda não mostrava fortes indícios de desaquecimento; já em 2015 a probabilidade de o indivíduo permanecer ocupado diminui. Uma análise mais minuciosa indica também que a saída da condição de ocupado refletiu a transição para o estado de inatividade mais do que para o de desocupado, possivelmente por razão de aposentadoria.

A evolução das transições a partir da desocupação está apresentada na Figura 2b, ou seja, dos indivíduos que no mês de referência se encontravam desocupados e que no período seguinte continuavam desocupados ou que transitaram para ocupados ou inativos. Deste modo, é possível observar que a probabilidade de indivíduos que não transitaram, ou seja, estavam desocupados em $t-1$ e continuaram desocupados em $t$, teve diminuição. Essa redução foi mais intensa, notadamente, quando se analisam os anos de 2010 até 2013, período em que a economia brasileira vinha apresentando taxas de crescimento econômico positivas, puxados principalmente pelas exportações, fortes investimentos no setor da construção civil, além do alto crescimento do setor de serviços, os dois últimos intensivos em mão de obra e, segundo apontaram Squeff e De Negri (2014), com crescente participação na geração de ocupações de 2005 a 2013.

(10) De acordo com a equação (1), enquanto em dezembro de $2002\left(X_{t}\right)$ a proporção de indivíduos que permaneceram ocupados, em relação ao total de ocupados em novembro $\left(X_{t-1}\right)$ desse ano, foi igual a 0,909 , em janeiro de 2003 , essa relação caiu para 0,887 , em relação a dezembro de 2002 . 
Chama a atenção a mudança de patamar que ocorreu ao final de 2010 do percentual daqueles que saíram da condição de desocupados e migraram para a de inativos, situação que se manteve até o início de 2015. Consideramos a hipótese de que tal comportamento refletiu o lançamento ou expansão de diversos programas sociais ao final do governo Lula e início do primeiro governo Dilma. Entre esses programas, destacam-se aqueles com foco na ampliação do acesso de jovens ao ensino universitário (Fundo de Financiamento Estudantil - FIES e Programa Universidade para Todos - Prouni) ou técnico (Programa Nacional de Acesso ao Ensino Técnico e Emprego - Pronatec) e o próprio programa Bolsa Família, todos cujos recursos disponíveis tiveram forte expansão até o final de $2014{ }^{11}$. Dados das PNADs de 2009 e 2013 mostrando expressiva queda, de 50,8\% para 48,9\%, no nível de ocupação de jovens na faixa etária de 18 a 19 anos favorecem a validade da nossa hipótese.

Por sua vez, a partir de 2014, com a economia mostrando sinais mais fortes de desaquecimento, a chance de os indivíduos que estavam desocupados de permanecerem neste estado apresentou aumento, refletindo tanto a queda do percentual daqueles que encontravam emprego quanto dos que migravam para a inatividade.

Figura 2

Estimativas das probabilidades de transição mensais no mercado

de trabalho metropolitano brasileiro, 2002-2015

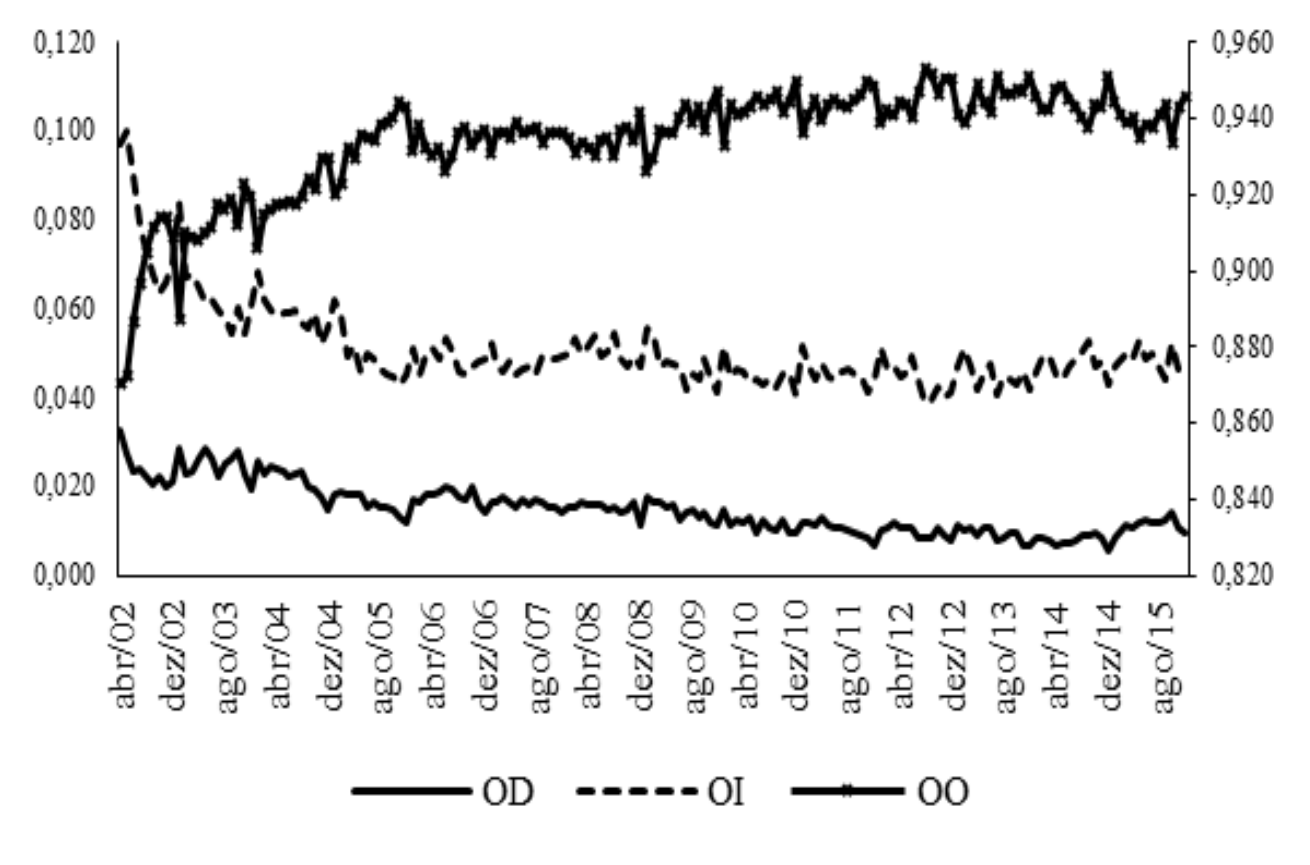

a) ocupação

(11) Em valores corrigidos para janeiro de 2016, os recursos alocados nos programas Bolsa Família, FIES e Prouni saltaram de R \$ 13,5 bilhões, R \$ 1,7 bilhão e R 580 milhões, em 2010, para R \$ 26,1 bilhões, R \$ 12,2 bilhões e R \$ 1,1 bilhão, em 2014, respectivamente. Já no Prouni, de 2011 para 2014, subiu de R \$ 2,0 bilhões para R \$ 5,3 bilhões, conforme informações do Ministério da Educação e Ministério do Desenvolvimento Social. 


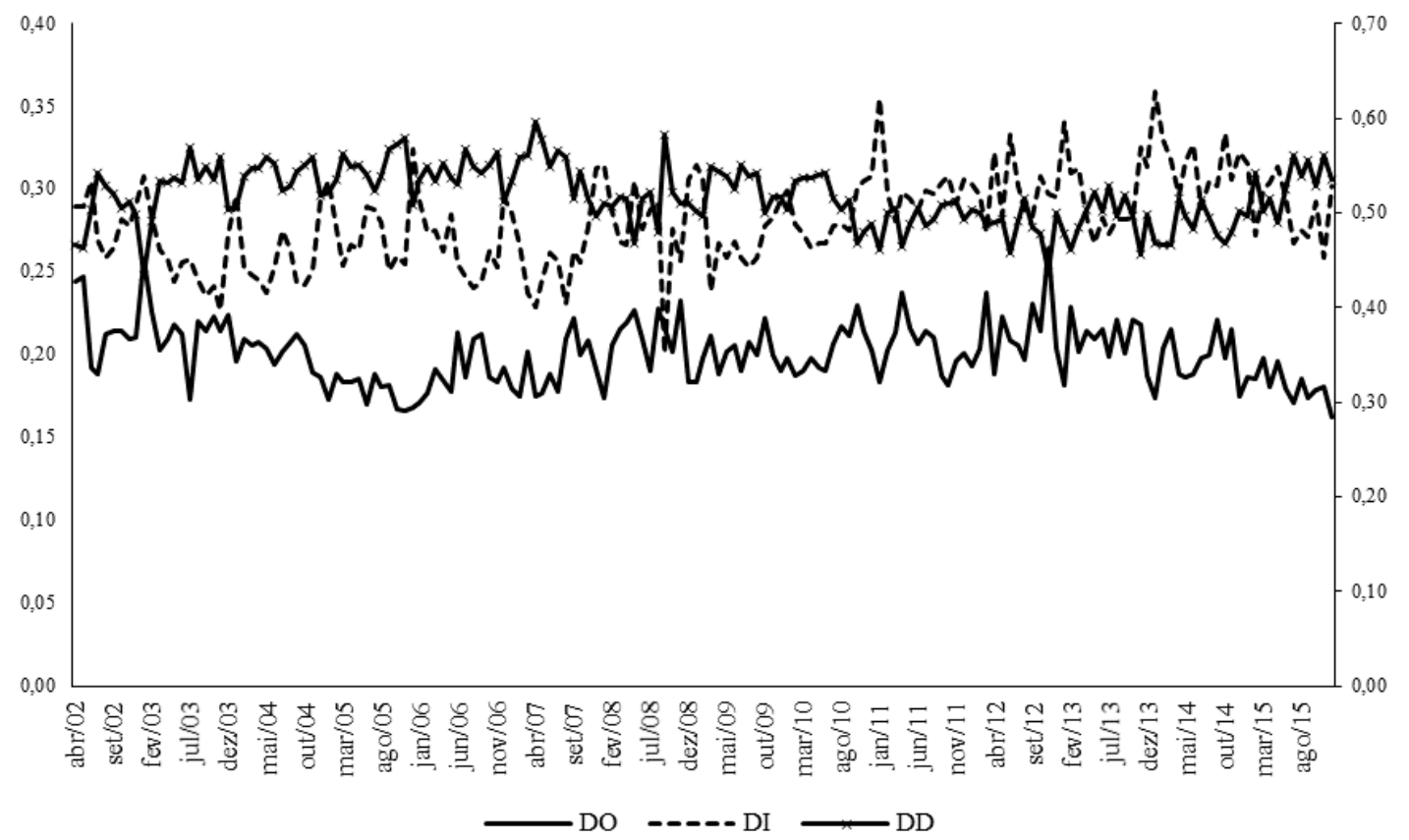

b) Desocupação

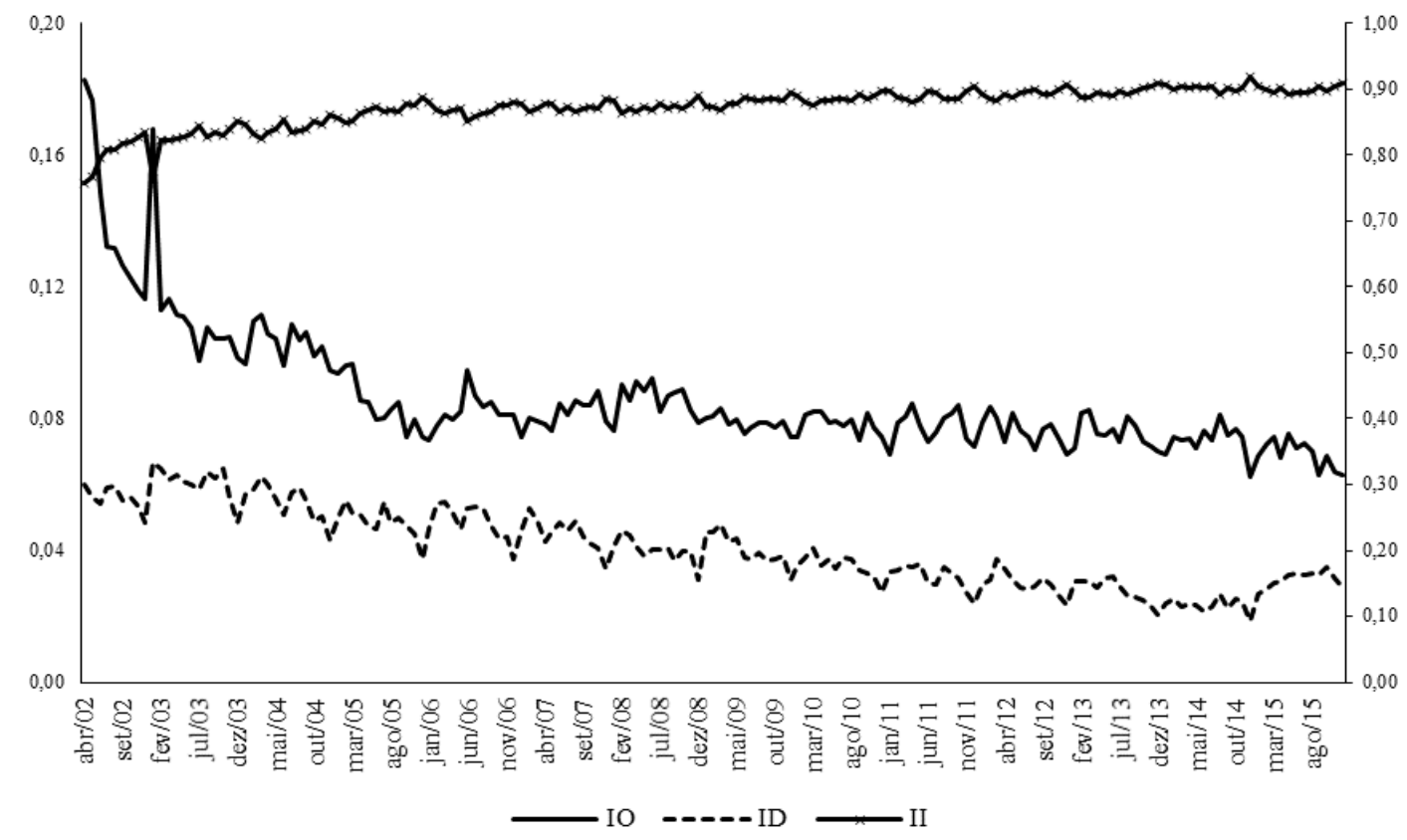

c) Inatividade

Fonte: Elaboração própria, a partir de informações da PME. 
Carlos Eduardo Gomes, Renata Lemos Lima, Marina Silva da Cunha, Marcos Roberto Vasconcelos

Em relação à inatividade (Figura 2c), verificamos aumento nas chances de os indivíduos não transitarem, ou seja, permaneceram inativos, especialmente até o ano de 2014. Apesar da relativa estabilidade nas chances de os indivíduos, a partir da inatividade, migrarem para a ocupação, em relação à transição para o estado de desocupado, ocorreu um decréscimo das chances até o ano de 2014. Porém, a partir de 2015, as chances de ir para a desocupação se elevam, devido à crise econômica, ou seja, pode-se perceber que as chances de os indivíduos entrarem ou regressarem no mercado de trabalho e irem para a desocupação aumenta.

Buscando verificar as evidências de que o comportamento no mercado de trabalho de homens e mulheres possui diferenças significativas, apresentamos na Tabela 2 as médias anuais das probabilidades de transição para cada sexo, que foram calculadas seguindo Clark e Summers (1979 e 1982) e Bivar (1993). Novamente, ressaltamos que em cada uma das três situações, ocupado, desocupado e inativo, as probabilidades somam 1, conforme descrito na metodologia.

Ao longo do período, observamos, para ambos os sexos, elevação da taxa de permanência nos estados de ocupado (OO) e inativo (II), sendo a alta mais pronunciada para as mulheres e homens no estado inativo. Já a taxa de permanência no estado desocupado (DD) tem tendência de queda entre 2007 a 2014, quando passa a ascender. O aumento das taxas de permanência de ocupado e inativo é provavelmente um indício da redução da população que se inseria no mercado de trabalho de forma informal, flutuando, dada a inexistência de contrato formal junto ao empregador, entre a ocupação e a inatividade, conforme a disponibilidade de trabalho. Isso está alinhado à observação de Cacciamali, Lima e Tatei (2010) de que houve aumento na demanda por trabalhadores a um ritmo superior ao da força de trabalho, fazendo com que o desemprego diminuísse e o banco de reservas formado por trabalhadores informais se reduzisse.

Como esperado, ao se analisar as transições dos indivíduos no mercado de trabalho, observamos maior estabilidade no estado de ocupado (OO), acima de 90\%, seguida da inatividade (II), também com percentuais próximos a $90 \%$ ao final do período. Já a permanência no estado desocupado apresentou maior variabilidade, embora até 2013 e 2014 apresentasse tendência de queda para os homens e mulheres, respectivamente, sofrendo acentuado aumento no ano de 2015. Ou seja, o maior fluxo das transições ocorre no desemprego (DD), em torno de 50\%, sendo que, no caso das mulheres, o fluxo do desemprego para a inatividade é mais intenso que o dos homens e o fluxo do desemprego para a ocupação é maior para eles em relação a elas.

De maneira geral, observamos que os efeitos da crise foram o aumento do número indivíduos no desemprego e a redução tanto na ocupação quanto na inatividade ao final do período estudado. Verificamos menor probabilidade de ocupação (OO), com indivíduos indo para o desemprego (OD), com mais intensidade, ou a inatividade (OI). No desemprego, a probabilidade de o indivíduo continuar desempregado (DD) aumenta e, simultaneamente, se 
reduzem as chances de ir para a ocupação (DO) ou para a inatividade (DI). A probabilidade de o indivíduo continuar inativo (II) também se restringe, elevando as chances dele de ir para o desemprego (ID), porém, reduzindo as chances de encontrar uma ocupação (IO). Há um aumento da População Economicamente Ativa (PEA), principalmente com mais mulheres participando do mercado de trabalho, sugerindo uma busca por complementação da renda familiar, provavelmente para compensar a queda de renda nominal ou real do chefe de família ou mesmo o fim de alguma complementação de renda do governo.

Tabela 2

Transições no mercado de trabalho metropolitano, homens e mulheres, Brasil, 2002-2015

\begin{tabular}{|c|c|c|c|c|c|c|c|c|c|}
\hline \multirow{3}{*}{ Ano } & \multicolumn{3}{|c|}{ Ocupado } & \multicolumn{3}{|c|}{ Desocupado } & \multicolumn{3}{|c|}{ Inativo } \\
\hline & $\mathrm{OO}$ & OD & $\mathrm{OI}$ & DO & DD & DI & $\mathrm{IO}$ & ID & II \\
\hline & \multicolumn{9}{|c|}{ Homem } \\
\hline 2002 & 0,920 & 0,025 & 0,054 & 0,279 & 0,498 & 0,223 & 0,204 & 0,074 & 0,722 \\
\hline 2003 & 0,933 & 0,025 & 0,042 & 0,275 & 0,525 & 0,200 & 0,154 & 0,077 & 0,769 \\
\hline 2004 & 0,938 & 0,022 & 0,040 & 0,261 & 0,535 & 0,204 & 0,139 & 0,065 & 0,795 \\
\hline 2005 & 0,951 & 0,015 & 0,034 & 0,224 & 0,548 & 0,229 & 0,109 & 0,062 & 0,829 \\
\hline 2006 & 0,949 & 0,017 & 0,033 & 0,235 & 0,548 & 0,216 & 0,106 & 0,062 & 0,832 \\
\hline 2007 & 0,952 & 0,015 & 0,033 & 0,235 & 0,547 & 0,217 & 0,103 & 0,055 & 0,842 \\
\hline 2008 & 0,952 & 0,014 & 0,034 & 0,259 & 0,507 & 0,235 & 0,109 & 0,048 & 0,843 \\
\hline 2009 & 0,953 & 0,014 & 0,033 & 0,248 & 0,525 & 0,227 & 0,099 & 0,049 & 0,852 \\
\hline 2010 & 0,958 & 0,011 & 0,031 & 0,246 & 0,517 & 0,237 & 0,098 & 0,042 & 0,860 \\
\hline 2011 & 0,959 & 0,010 & 0,031 & 0,252 & 0,490 & 0,258 & 0,095 & 0,039 & 0,867 \\
\hline 2012 & 0,960 & 0,009 & 0,031 & 0,256 & 0,485 & 0,259 & 0,092 & 0,037 & 0,870 \\
\hline 2013 & 0,959 & 0,009 & 0,032 & 0,250 & 0,485 & 0,265 & 0,094 & 0,035 & 0,871 \\
\hline 2014 & 0,958 & 0,008 & 0,035 & 0,235 & 0,492 & 0,273 & 0,091 & 0,029 & 0,880 \\
\hline 2015 & 0,953 & 0,012 & 0,036 & 0,215 & 0,536 & 0,249 & 0,086 & 0,040 & 0,874 \\
\hline \multicolumn{10}{|l|}{ Mulher } \\
\hline 2002 & 0,869 & 0,021 & 0,110 & 0,158 & 0,510 & 0,332 & 0,113 & 0,048 & 0,839 \\
\hline 2003 & 0,885 & 0,025 & 0,090 & 0,167 & 0,531 & 0,301 & 0,096 & 0,054 & 0,850 \\
\hline 2004 & 0,895 & 0,022 & 0,083 & 0,157 & 0,544 & 0,299 & 0,088 & 0,051 & 0,861 \\
\hline 2005 & 0,914 & 0,017 & 0,069 & 0,144 & 0,545 & 0,311 & 0,074 & 0,043 & 0,882 \\
\hline 2006 & 0,913 & 0,018 & 0,069 & 0,156 & 0,540 & 0,304 & 0,072 & 0,043 & 0,885 \\
\hline 2007 & 0,916 & 0,017 & 0,067 & 0,159 & 0,550 & 0,291 & 0,072 & 0,041 & 0,887 \\
\hline 2008 & 0,913 & 0,017 & 0,070 & 0,173 & 0,517 & 0,310 & 0,076 & 0,037 & 0,887 \\
\hline 2009 & 0,920 & 0,015 & 0,064 & 0,163 & 0,529 & 0,307 & 0,070 & 0,037 & 0,894 \\
\hline 2010 & 0,926 & 0,012 & 0,062 & 0,172 & 0,514 & 0,314 & 0,070 & 0,032 & 0,897 \\
\hline 2011 & 0,926 & 0,011 & 0,063 & 0,171 & 0,497 & 0,331 & 0,070 & 0,029 & 0,900 \\
\hline 2012 & 0,930 & 0,011 & 0,060 & 0,185 & 0,487 & 0,328 & 0,069 & 0,027 & 0,904 \\
\hline 2013 & 0,930 & 0,010 & 0,060 & 0,178 & 0,504 & 0,317 & 0,068 & 0,024 & 0,908 \\
\hline 2014 & 0,929 & 0,008 & 0,063 & 0,168 & 0,481 & 0,351 & 0,066 & 0,021 & 0,914 \\
\hline 2015 & 0,926 & 0,011 & 0,063 & 0,151 & 0,528 & 0,320 & 0,061 & 0,027 & 0,912 \\
\hline
\end{tabular}

Fonte: Elaboração própria a partir de informações da PME. 
Carlos Eduardo Gomes, Renata Lemos Lima, Marina Silva da Cunha, Marcos Roberto Vasconcelos

Mostramos nesta seção que, apesar da crise no ano de 2015, o mercado de trabalho se encontrou, ao final do período analisado, em melhores condições que no seu início, em 2002. Tanto as chances de se manter ocupado eram maiores, quanto as de se ir para a desocupação a partir da ocupação eram menores. Por sua vez, as chances de se manter desempregado para homens e mulheres voltaram, em 2015, a patamares próximos aos de 2003, refletindo a perda de capacidade de a economia gerar novas vagas de trabalho. A próxima etapa da crise seria o fechamento de postos de trabalho, o que acabou acontecendo em 2016, e a efetiva queda no número de pessoas ocupadas.

Assim, quando se analisa os anos finais da amostra, é possível notar que a crise econômica rapidamente alastrou seus efeitos pelo mercado de trabalho: a probabilidade de encontrar um emprego saindo do estado de desocupação ou de inatividade se reduziu, fazendo com que o tempo de permanência dos indivíduos nestes estados aumentasse.

\section{Resultados e discussões}

De maneira geral, as estimativas dos modelos logit multinomial foram estatisticamente significativas. Com relação à hipótese da Independência das Alternativas Irrelevantes (IIA), as estimativas do modelo apresentaram bons resultados, não rejeitando a hipótese nula de independência, ou seja, a inclusão ou a exclusão de categorias não afeta os resultados das estimativas. Além disso, ao estimarmos as duas especificações, sem e com controle para sazonalidade, ciclo econômico e região, verificamos resultados similares e que confirmaram os sinais dos coeficientes estimados.

Os resultados das estimativas econométricas com as transições a partir da ocupação, em razão de chances, estão apresentados na Tabela 3, tanto para homens quanto para as mulheres. Os dados da PME e a extensão de tempo considerados nestas estimativas nos permitiram traçar algumas características dos indivíduos que se mostram capazes de afetar as suas chances de transitar da ocupação para o desemprego ou para a inatividade no mercado de trabalho brasileiro.

Com relação à idade, que pode ser considerada proxy da experiência do indivíduo no mercado de trabalho, verificamos, como esperado, redução nas chances de ir para a inatividade ou para o desemprego, a partir da ocupação, conforme se elevam os anos de vida do trabalhador. Tal estimativa está também alinhada com o maior nível de desemprego e de rotatividade observado entre os jovens. A relação entre idade e chance de transição a partir da ocupação fica menor de forma mais rápida entre os mais jovens devido ao termo ao quadrado e pode voltar a crescer para os mais velhos, quando a estimativa do ponto de mínimo ocorre durante o ciclo de vida no mercado de trabalho. Conforme o esperado, considerando que o indivíduo está ocupado, a transição para o desemprego mostra-se decrescente para homens e mulheres, ou seja, as chances de transição da ocupação para o desemprego são menores quanto maior sua experiência em determinado posto de trabalho, devido ao custo de 
oportunidade de mudança para um novo emprego ${ }^{12}$. Por sua vez, as estimativas da transição da ocupação para a inatividade sugerem que no caso dos homens as menores chances de transição para fora do mercado de trabalho ocorrem aos 35 anos e para as mulheres aos 38 anos, e são maiores para os mais jovens e mais velhos.

Tabela 3

Resultados do modelo logit multinomial para as transições a partir dos ocupados, no mercado de trabalho metropolitano, Brasil, 2002-2015

\begin{tabular}{|c|c|c|c|c|c|c|c|c|}
\hline \multirow{4}{*}{$\begin{array}{l}\text { Variáveis } \\
\text { Idade }\end{array}$} & \multicolumn{4}{|c|}{ Homem } & \multicolumn{4}{|c|}{ Mulher } \\
\hline & \multicolumn{2}{|c|}{ Especificação 1} & \multicolumn{2}{|c|}{ Especificação 2} & \multicolumn{2}{|c|}{ Especificação 1} & \multicolumn{2}{|c|}{ Especificação 2} \\
\hline & \multicolumn{2}{|l|}{ OD } & \multicolumn{2}{|l|}{ OD } & \multirow{2}{*}{$\begin{array}{l}\text { OD } \\
0,931 *\end{array}$} & \multirow{2}{*}{$\frac{\text { OI }}{0,894^{*}}$} & \multirow{2}{*}{$\begin{array}{c}\text { OD } \\
0,932 *\end{array}$} & \multirow{2}{*}{$\frac{\text { OI }}{0,892 *}$} \\
\hline & $0,940 *$ & $0,891^{*}$ & $0,944^{*}$ & $0,891^{*}$ & & & & \\
\hline Idade $^{2}$ & $1,000^{*}$ & $1,001^{*}$ & $1,000^{*}$ & $1,001 *$ & $1,000 *$ & $1,001 *$ & $1,000 *$ & $1,001^{*}$ \\
\hline 1 a 3 anos de estudo & $0,880^{*}$ & $0,670 *$ & $0,899 *$ & $0,674 *$ & $0,949 *$ & $0,714 *$ & $0,967 *$ & $0,738^{*}$ \\
\hline 4 a 7 anos de estudo & $0,765^{*}$ & $0,578^{*}$ & $0,826^{*}$ & $0,593^{*}$ & $0,838^{*}$ & $0,636^{*}$ & $0,891 *$ & $0,667 *$ \\
\hline $\begin{array}{l}8 \text { a } 10 \text { anos de } \\
\text { estudo }\end{array}$ & $0,649^{*}$ & $0,445^{*}$ & $0,758^{*}$ & $0,477 *$ & $0,720 *$ & $0,534 *$ & $0,824 *$ & $0,581 *$ \\
\hline $11+$ anos de estudo & $0,407 *$ & $0,259 *$ & $0,492 *$ & $0,280 *$ & $0,453^{*}$ & $0,267 *$ & $0,534^{*}$ & $0,290 *$ \\
\hline Preta & $1,203^{*}$ & $1,058 *$ & $1,376^{*}$ & $1,081 *$ & $1,284^{*}$ & $0,886^{*}$ & $1,381^{*}$ & $0,917 *$ \\
\hline Parda & $1,194 *$ & $1,145^{*}$ & $1,209 *$ & $1,034 *$ & $1,222 *$ & $1,097 *$ & $1,213^{*}$ & $1,003 *$ \\
\hline Filho & $1,991 *$ & $2,759 *$ & $2,045 *$ & $2,693^{*}$ & $1,251 *$ & $1,222 *$ & $0,815^{*}$ & $1,230 *$ \\
\hline Cônjuge & $1,238^{*}$ & $1,293^{*}$ & $1,205^{*}$ & $1,128 *$ & $0,804 *$ & $1,500 *$ & $1,247^{*}$ & $1,583^{*}$ \\
\hline Outra condição & $1,703 *$ & $2,152 *$ & $1,748 *$ & $2,092 *$ & $1,269 *$ & $1,426^{*}$ & $1,265^{*}$ & $1,416^{*}$ \\
\hline Filhos de até 5 anos & $1,037 *$ & $0,762 *$ & $0,991 *$ & $0,741 *$ & $1,267 *$ & $1,420 *$ & $1,244^{*}$ & $1,391 *$ \\
\hline Constante & $0,104 *$ & $0,318 *$ & $0,155 *$ & $0,608 *$ & $0,220 *$ & $0,903 *$ & $0,313^{*}$ & $1,520 *$ \\
\hline Controle sazonal & \multicolumn{2}{|c|}{ NÃO } & \multicolumn{2}{|c|}{ SIM } & \multicolumn{2}{|c|}{ NÃO } & \multicolumn{2}{|c|}{ SIM } \\
\hline Controle de ciclo & \multicolumn{2}{|c|}{ NÃO } & \multicolumn{2}{|c|}{ SIM } & \multicolumn{2}{|c|}{ NÃO } & \multicolumn{2}{|c|}{ SIM } \\
\hline Controle de região & \multicolumn{2}{|c|}{ NÃO } & \multicolumn{2}{|c|}{ SIM } & \multicolumn{2}{|c|}{ NÃO } & \multicolumn{2}{|c|}{ SIM } \\
\hline Amostra & \multicolumn{2}{|c|}{2.818 .240} & \multicolumn{2}{|c|}{2.818 .240} & \multicolumn{2}{|c|}{2.303 .365} & \multicolumn{2}{|c|}{2.303 .365} \\
\hline Pseudo R ${ }^{2}$ & \multicolumn{2}{|c|}{0.0639} & \multicolumn{2}{|c|}{0,0861} & \multicolumn{2}{|c|}{0,0493} & \multicolumn{2}{|c|}{0,0687} \\
\hline
\end{tabular}

Fonte: Elaboração própria a partir das informações da PME. Observações: * resultados estatisticamente significativos ao nível de 5\%. Modelo estimado utilizando a razão de chances, em que a categoria base é OO.

Em relação à escolaridade, tendo como base indivíduos com menos de um ano de instrução escolar, inferimos redução nas chances de o indivíduo sair da condição de ocupado conforme seus anos de estudo aumentem, sendo tal efeito mais acentuado para os homens do que para as mulheres. No caso de transição para a inatividade, o impacto da escolaridade

(12) Na transição da ocupação para o desemprego, o termo ao quadrado indica que as chances de transição não se reduzem de forma linear, mas de forma mais intensa para os mais jovens e, posteriormente, esta redução nas chances de transição ocorre de maneira mais lenta para os indivíduos até o final de seu ciclo de vida no mercado de trabalho, em torno de setenta anos, uma vez que tanto para homens como para mulheres o ponto de mínimo ocorreu após essa idade. 
mostrou-se ainda mais significativo, indicando que o acréscimo de anos de estudo permite aos trabalhadores maiores condições de permanecer no mercado de trabalho, mesmo na situação de desocupado. Isso corroboram as evidências encontradas por Monte, Ramalho e Pereira (2011) indicando que o salário de reserva médio mais que dobra para indivíduos com 13 anos ou mais de escolaridade. Assim, as chances de os indivíduos mais instruídos estarem no mercado de trabalho são maiores do que as de permanecerem fora do mesmo. Esses resultados são válidos tanto para homens quanto para mulheres.

De acordo com Cacciamali, Lima e Tatei (2010), ao se acompanhar o crescimento da escolaridade da população brasileira, o grupo de desempregados se tornou, em média, mais qualificado. Porém, devido ao ritmo mais acelerado de absorção dos desempregados com escolaridade e qualificação mais elevada, a proporção dos trabalhadores desocupados com menos anos de estudo cresceu.

Em relação à raça/cor, verificamos que indivíduos da cor preta e parda se mostraram com maiores chances de transitarem da condição de ocupado para a de desempregado, tanto no caso dos homens quanto no das mulheres. Ou seja, indivíduos não brancos transitam mais no mercado de trabalho brasileiro, o que para Oliveira, Scorzafave e Pazello (2009) seria esperado, em função do potencial efeito discriminatório e de características não observáveis, como a qualidade da educação, que tem efeitos sobre a maior chance de desemprego/inatividade deste grupo. Lembramos que em nossas estimativas controlamos fatores como anos de estudo, idade e, na especificação 2, inclusive fatores regionais, e, mesmo assim, o coeficiente estimado para a cor dos indivíduos indica maiores chances daqueles da cor preta migrarem da situação de ocupado para a de desocupado. Considerando que não existem escolas exclusivas para indivíduos de cada cor, podemos assumir como bem provável a existência de discriminação no mercado de trabalho brasileiro ou, em menor probabilidade, que o diferencial de qualidade na educação ocorra dentro das salas de aula ${ }^{13}$.

Chama a atenção ainda, o fato de as mulheres negras terem menores chances de transitar da situação de ocupada para a de inativa do que mulheres brancas. Isso pode indicar alta proporção de mulheres negras na condição de chefe de família ou que, mesmo na condição de cônjuge, se veem obrigadas a permanecerem no mercado de trabalho em busca de um emprego devido à essencialidade de sua renda para a subsistência familiar.

Alinhada com a estimativa referente à idade, encontramos que as chances de transição dos filhos para a desocupação ou para a inatividade são maiores quando comparados às chances do indivíduo na condição de chefe de família, a categoria de referência. Este cenário pode estar relacionado com a entrada do jovem no mercado de trabalho. Se, por um lado, contribuem menos para a renda domiciliar quando comparados aos chefes de família e, por isso, possuem menor custo de oportunidade, por outro, quando ingressam no mercado de trabalho transitam da ocupação para desocupação ou inatividade

(13) Acrescenta-se à discriminação aqui mostrada aquela apontada por Soares (2000) e que explicaria a significativa parcela dos diferenciais negativos de salários de homens e mulheres da cor preta em relação ao homem da cor branca. 
Transições no mercado de trabalho brasileiro e os efeitos imediatos da crise econômica dos anos 2010

mais intensamente pela dificuldade em conseguir o primeiro emprego ou pela alta rotatividade no emprego. Assim, quanto mais jovens, maiores as chances de transição, o que confirma os resultados encontrados por Flori (2003), que concluiu que os jovens possuem maior rotatividade devido à baixa duração nos empregos.

Conforme Flori (2003), quem não consegue ou não quer encontrar ou se manter no emprego, em períodos mais aquecidos da economia, pode optar por se qualificar, para assim ser futuramente mais competitivo no mercado de trabalho e auferir maiores rendimentos. Talvez essa busca por mais qualificação posterior ao evento de saída da situação de ocupado seja mais elevado em jovens mulheres do que em rapazes. Outra hipótese possível é o afastamento do mercado de trabalho das jovens estar vinculada ao matrimônio. Já a menor chance de migrar para o estado de desocupada pode estar vinculada ao maior número de anos de estudo das mulheres jovens ${ }^{14}$.

Destacamos também as estimativas que mostram elevadas chances de o homem na condição de cônjuge, quando comparado ao na condição de chefe de família, transitar da ocupação para o desemprego ou inatividade. Provavelmente, isso reflete uma capacidade destes homens, por não serem os principais responsáveis pela renda familiar, de sair do emprego e buscar ou aguardar uma melhor oportunidade de trabalho. Assim, verificamos que principalmente os homens na condição de cônjuge transitam mais que os chefes de família. Segundo Oliveira, Scorzafave e Pazello (2009), isso se deve ao custo de oportunidade de estar desocupado ou inativo, que é maior para o chefe de família, uma vez que este se constitui no maior provedor de recursos no domicílio.

Em relação aos domicílios com presença de crianças até cinco anos de idade, as chances de transições no mercado de trabalho brasileiro diferem entre homens e mulheres. Para os homens há maior chance de permanecer no mercado de trabalho, enquanto para as mulheres essa característica resulta em queda nas chances de participação. De fato, a estimativa indica que o trabalhador com filhos de até 5 anos possui chance menor de ir para a inatividade do que aquele sem tal condição, enquanto para a trabalhadora é o oposto. Este resultado se relaciona possivelmente às estruturas sociais prevalecentes, em que a mulher é a cuidadora do lar e dos filhos, desestimulando a sua entrada ou permanência no mercado de trabalho, enquanto o homem ainda teria o papel de provedor e principal responsável pela renda familiar, tornando assim o seu custo de oportunidade de não trabalhar mais elevado. De acordo com Oliveira, Scorzafave e Pazello (2009), um dos motivos de a mulher que possui filhos de até cinco anos transitar menos para o mercado de trabalho ocorre pela necessidade das mulheres de conciliar a atividade no mercado de trabalho com o cuidado com os filhos, tendendo assim a preferir postos de trabalho com jornadas mais flexíveis, o que aumenta sua chance de transitar para o desemprego devido à dificuldade de encontrar uma ocupação com tais características.

(14) Segundo dados expostos por Venturi e Torini (2014), 26,6\% das mulheres na faixa etária de 20 a 24 anos ainda continuavam estudando ante a 20,4\% dos homens em igual idade, conforme pesquisa feita em 2013. 
As estimativas para as chances de transição a partir do desemprego estão apresentadas na Tabela 4. Em relação à idade, são maiores as chances de transição a partir da desocupação para a ocupação conforme a elevação da idade, ou seja, com o aumento da experiência. Já ao final do ciclo de vida, estas chances se reduzem. Conforme o esperado, o contrário foi observado com as transições para a inatividade.

A escolaridade tem efeito distinto nas chances de transição do desemprego para a ocupação para homens e mulheres. No caso deles, o efeito é monotonicamente negativo conforme se avança na educação formal, o que pode ser explicado pelo maior salário de reserva e uma maior seletividade para a ocupação de uma vaga no mercado de trabalho. Para as mulheres a relação, apesar de também ser negativa quando comparada à categoria de referência, fica menos forte para as mais escolarizadas, sugerindo que elas estão conseguindo encontrar mais rapidamente novos postos de trabalho ou são menos seletivas na busca por nova ocupação. Por sua vez, a escolaridade reduz as chances de transição para a inatividade, tanto para eles quanto para elas, sendo tal efeito mais acentuado para as mulheres com nível universitário.

Tabela 4

Resultados do modelo logit multinomial para as transições a partir dos desempregados, no mercado de trabalho metropolitano, Brasil, 2002-2015

\begin{tabular}{|c|c|c|c|c|c|c|c|c|}
\hline \multirow{4}{*}{$\begin{array}{l}\text { Variáveis } \\
\text { Idade }\end{array}$} & \multicolumn{4}{|c|}{ Homem } & \multicolumn{4}{|c|}{ Mulher } \\
\hline & \multicolumn{2}{|c|}{ Especificação 1} & \multicolumn{2}{|c|}{ Especificação 2} & \multicolumn{2}{|c|}{ Especificação 1} & \multicolumn{2}{|c|}{ Especificação 2} \\
\hline & \multicolumn{2}{|l|}{ DO } & \multicolumn{2}{|l|}{ DO } & \multicolumn{2}{|l|}{ DO } & \multirow{2}{*}{$\frac{\mathrm{DO}}{1,060^{*}}$} & DI \\
\hline & $1,045^{*}$ & $0,925^{*}$ & $1,043 *$ & $0,919^{*}$ & $1,057^{*}$ & $0,953^{*}$ & & $0,950^{*}$ \\
\hline Idade $^{2}$ & $0,999 *$ & $1,001 *$ & $0,999 *$ & $1,001^{*}$ & $0,999 *$ & $1,000 *$ & $0,999 *$ & $1,000^{*}$ \\
\hline 1 a 3 anos de estudo & $0,849^{*}$ & $0,789 *$ & $0,877^{*}$ & $0,808^{*}$ & $0,831 *$ & $0,722 *$ & $0,854^{*}$ & $0,744^{*}$ \\
\hline 4 a 7 anos de estudo & $0,796 *$ & $0,733^{*}$ & $0,807^{*}$ & $0,730 *$ & $0,920 *$ & $0,738^{*}$ & $0,928 *$ & $0,748 *$ \\
\hline 8 a 10 anos de estudo & $0,639^{*}$ & $0,656^{*}$ & $0,666^{*}$ & $0,654 *$ & $0,816^{*}$ & $0,687 *$ & $0,837 *$ & $0,698 *$ \\
\hline $11+$ anos de estudo & $0,595 *$ & $0,592 *$ & $0,628^{*}$ & $0,576^{*}$ & $0,881 *$ & $0,564 *$ & $0,905^{*}$ & $0,559 *$ \\
\hline Preta & $0,854 *$ & $0,880^{*}$ & $1,001 *$ & $0,897 *$ & $0,785^{*}$ & $0,802 *$ & $0,935 *$ & $0,861 *$ \\
\hline Parda & $0,995 *$ & $1,029 *$ & $1,033^{*}$ & $0,942 *$ & $0,888^{*}$ & $0,971 *$ & $0,949 *$ & $0,928 *$ \\
\hline Filho & $0,658^{*}$ & $1,330 *$ & $0,648^{*}$ & $1,279^{*}$ & $0,810^{*}$ & $0,970 *$ & $0,854^{*}$ & $1,002 *$ \\
\hline Cônjuge & $1,089 *$ & $1,123^{*}$ & $1,008^{*}$ & 0,999 & $0,797 *$ & $1,250 *$ & $0,863^{*}$ & $1,360 *$ \\
\hline Outra condição & $0,734 *$ & $1,335^{*}$ & $0,734 *$ & $1,268^{*}$ & $0,798^{*}$ & $1,057 *$ & $0,855^{*}$ & $1,089 *$ \\
\hline Filhos de até 5 anos & $1,137 *$ & $0,907 *$ & $1,113^{*}$ & $0,901 *$ & $0,920^{*}$ & $1,125 *$ & $0,911 *$ & $1,123 *$ \\
\hline Constante & $0,471 *$ & $1,688^{*}$ & $0,315^{*}$ & $2,089 *$ & $0,178^{*}$ & $1,715^{*}$ & $0,098 *$ & $1,792 *$ \\
\hline Controle sazonal & \multicolumn{2}{|c|}{ NÃO } & \multicolumn{2}{|c|}{ SIM } & \multicolumn{2}{|c|}{ NÃO } & \multicolumn{2}{|c|}{ SIM } \\
\hline Controle de ciclo & \multicolumn{2}{|c|}{ NÃO } & \multicolumn{2}{|c|}{ SIM } & \multicolumn{2}{|c|}{ NÃO } & \multicolumn{2}{|c|}{ SIM } \\
\hline Controle de região & \multicolumn{2}{|c|}{ NÃO } & \multicolumn{2}{|c|}{ SIM } & \multicolumn{2}{|c|}{ NÃO } & \multicolumn{2}{|c|}{ SIM } \\
\hline Amostra & \multicolumn{2}{|c|}{192.392} & \multicolumn{2}{|c|}{192.392} & \multicolumn{2}{|c|}{250.247} & \multicolumn{2}{|c|}{250.247} \\
\hline Pseudo $\mathrm{R}^{2}$ & \multicolumn{2}{|c|}{0,0166} & \multicolumn{2}{|c|}{0,0388} & \multicolumn{2}{|c|}{0,0092} & \multicolumn{2}{|c|}{0,0320} \\
\hline
\end{tabular}

Fonte: Elaboração própria a partir das informações da PME. Observações: * resultados estatisticamente significativos ao nível de 5\%. Modelo estimado utilizando a razão de chances, em que a categoria base é DD. 
Novamente as estimativas apresentam indícios de discriminação, ou de outros fatores não considerados, adversa aos indivíduos da cor preta, pois estes possuem menores chances de migrarem da condição de desocupado para a de ocupado quando comparados aos brancos ou pardos. O mesmo observamos quanto à migração para a inatividade. $\mathrm{E}$ ambos os efeitos se mostraram mais acentuados para as mulheres.

Por sua vez, considerando a condição na família, destacamos as menores chances de transição do desemprego para a ocupação e as maiores para a inatividade, especialmente na Especificação 2, quando os controles para sazonalidade, ciclo anual e região estão incluídos. Os homens com filhos de até cinco anos têm maiores chances de ir para a ocupação e menores de ir para a inatividade, sendo o oposto observado para as mulheres, conforme o esperado, devido ao maior custo de oportunidade delas. A combinação das estimativas de que homens com filhos de até 5 anos tem maiores chances de migrar da situação de desocupado para ocupado com as de que eles teriam maiores chances de fazer a transição inversa talvez reflita o que poderíamos denominar de um "efeito paternidade" capaz de tornar os homens mais empenhados, portanto mais produtivos no trabalho, e menos seletivos em relação às suas ocupações.

Na Tabela 5 podem ser observadas as estimativas das chances de transição a partir da inatividade. Nos casos de idade, educação e raça os resultados são similares, tanto para homens quanto para mulheres. Assim, conforme a idade se eleva as chances de transição para o

Tabela 5

Resultados do modelo logit multinomial para as transições a partir da inatividade, no mercado de trabalho metropolitano, Brasil, 2002-2015

\begin{tabular}{|c|c|c|c|c|c|c|c|c|}
\hline \multirow{3}{*}{ Variáveis } & \multicolumn{4}{|c|}{ Homem } & \multicolumn{4}{|c|}{ Mulher } \\
\hline & \multicolumn{2}{|c|}{ Especificação 1} & \multicolumn{2}{|c|}{ Especificação 2} & \multicolumn{2}{|c|}{ Especificação 1} & \multicolumn{2}{|c|}{ Especificação 2} \\
\hline & \multicolumn{2}{|c|}{ IO $\quad$ ID } & \multicolumn{2}{|l|}{ IO } & \multicolumn{2}{|l|}{$\mathrm{IO}$} & $\mathrm{IO}$ & ID \\
\hline Idade & $1,101 *$ & $1,165^{*}$ & $1,094 *$ & $1,156^{*}$ & $1,142 *$ & $1,124 *$ & $1,139 *$ & $1,121 *$ \\
\hline Idade $^{2}$ & $0,998 *$ & $0,997 *$ & $0,998 *$ & $0,997 *$ & $0,998 *$ & $0,997 *$ & $0,998 *$ & $0,997 *$ \\
\hline 1 a 3 anos de estudo & $1,699 *$ & $2,624 *$ & $1,702 *$ & $2,592 *$ & $1,348^{*}$ & $1,922 *$ & $1,376^{*}$ & $1,946^{*}$ \\
\hline 4 a 7 anos de estudo & $1,712 *$ & $3,082 *$ & $1,787 *$ & $3,159 *$ & $1,533^{*}$ & $2,135^{*}$ & $1,609^{*}$ & $2,240 *$ \\
\hline 8 a 10 anos de estudo & $1,687 *$ & $3,532 *$ & $1,915^{*}$ & $3,990 *$ & $1,580 *$ & $2,324 *$ & $1,774 *$ & $2,625^{*}$ \\
\hline $11+$ anos de estudo & $1,933 *$ & $4,038 *$ & $2,293 *$ & $4,794 *$ & $2,143^{*}$ & $3,065^{*}$ & $2,508 *$ & $3,652 *$ \\
\hline Preta & $1,024 *$ & $1,183 *$ & $1,157 *$ & $1,387 *$ & $1,170 *$ & $1,370 *$ & $1,326^{*}$ & $1,555^{*}$ \\
\hline Parda & $1,164 *$ & $1,252 *$ & $1,164 *$ & $1,309^{*}$ & $1,098^{*}$ & $1,254 *$ & $1,135^{*}$ & $1,326^{*}$ \\
\hline Filho & $0,444 *$ & $0,756^{*}$ & $0,452 *$ & $0,789 *$ & $0,814^{*}$ & $0,985^{*}$ & $0,850^{*}$ & $1,025^{*}$ \\
\hline Cônjuge & $1,236^{*}$ & $1,170 *$ & $1,184 *$ & $1,169 *$ & $0,566^{*}$ & $0,518 *$ & $0,583^{*}$ & $0,892 *$ \\
\hline Outra condição & $0,620 *$ & $0,824 *$ & $0,632 *$ & $0,879 *$ & $0,735^{*}$ & $0,865^{*}$ & $0,757 *$ & $0,892 *$ \\
\hline Filhos de até 5 anos & $1,473 *$ & $1,377 *$ & $1,431 *$ & $1,337 *$ & $0,742 *$ & $0,924 *$ & $0,717 *$ & $0,893 *$ \\
\hline Constante & $0,063 *$ & $0,007 *$ & $0,085^{*}$ & $0,009 *$ & $0,014 *$ & $0,013 *$ & $0,015^{*}$ & $0,015^{*}$ \\
\hline Controle sazonal & \multicolumn{2}{|c|}{ NÃO } & \multicolumn{2}{|c|}{ SIM } & \multicolumn{2}{|c|}{ NÃO } & \multicolumn{2}{|c|}{ SIM } \\
\hline Controle de ciclo & \multicolumn{2}{|c|}{ NÃO } & \multicolumn{2}{|c|}{ SIM } & \multicolumn{2}{|c|}{ NÃO } & \multicolumn{2}{|c|}{ SIM } \\
\hline Controle de região & \multicolumn{2}{|c|}{ NÃO } & \multicolumn{2}{|c|}{ SIM } & \multicolumn{2}{|c|}{ NÃO } & \multicolumn{2}{|c|}{ SIM } \\
\hline Amostra & \multicolumn{2}{|c|}{944.365} & \multicolumn{2}{|c|}{944.365} & \multicolumn{2}{|c|}{2.170 .457} & \multicolumn{2}{|c|}{2.170 .457} \\
\hline Pseudo $\mathrm{R}^{2}$ & \multicolumn{2}{|c|}{0,1456} & \multicolumn{2}{|c|}{0,1672} & \multicolumn{2}{|c|}{0,1211} & \multicolumn{2}{|c|}{0,1374} \\
\hline
\end{tabular}


mercado de trabalho, seja ao estado de desocupado ou de ocupado, se ampliam, mas passam a se reduzir ao final do ciclo de vida. Já no caso da educação, há relação positiva entre o nível de escolaridade e as chances de entrada ou retorno ao mercado de trabalho. Os pardos e pretos apresentam maiores chances de sair da inatividade que os brancos, mas isso pode refletir uma maior dificuldade em se manter nesta condição, devido a baixa ou inexistente reserva monetária e, por conseguinte, uma busca mais premente e menos seletiva por ocupação. Já com relação ao chefe de família, apenas os filhos têm maiores chances de transitarem da inatividade para a participação no mercado de trabalho, o que não ocorre, em geral, no caso das filhas, dos cônjuges e dos demais membros da família. Conforme o esperado, as chances deles migrarem para o mercado de trabalho quando têm filhos menores são maiores do que as chances das mulheres.

Por fim, é importante analisar os efeitos do ciclo anual, especialmente no final do período, quando a economia brasileira adentra uma fase recessiva. Para tanto, na Figura 3, estão apresentadas as estimativas das variáveis binárias anuais para a especificação 2, nas seis regressões. Em geral, os resultados corroboram com a análise descritiva e os efeitos esperados da crise econômica para o mercado de trabalho brasileiro. Vale salientar que estes resultados estão em razão de chances e, portanto, valores superiores à unidade indicam que as chances de transição são maiores que as observadas em 2002, ano de referência, e o contrário para valores menores que a unidade. Ademais, estas estimativas estão controladas para as demais variáveis incluídas na regressão, tais como ciclo sazonal, efeito das regiões e das características sócio-demográficas individuais.

\section{Figura 3}

Resultados das estimativas das variáveis binárias anuais para o ciclo econômico, para as transições a partir dos ocupados, desocupados e inativos no mercado de trabalho metropolitano, Brasil, 2002-2015

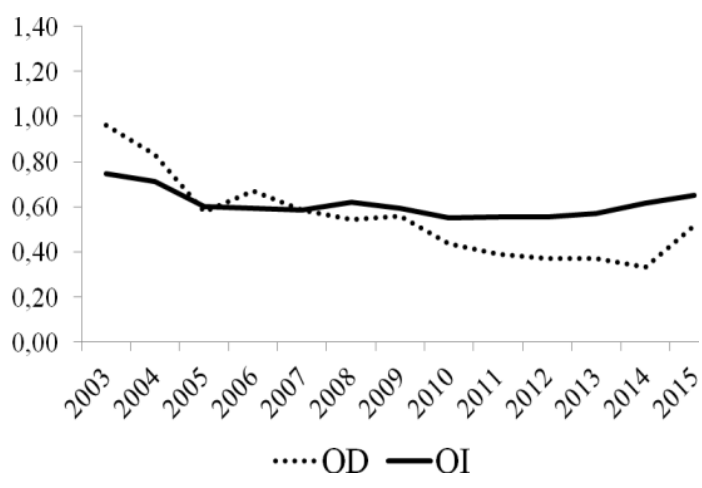

a) Homem (ocupação)

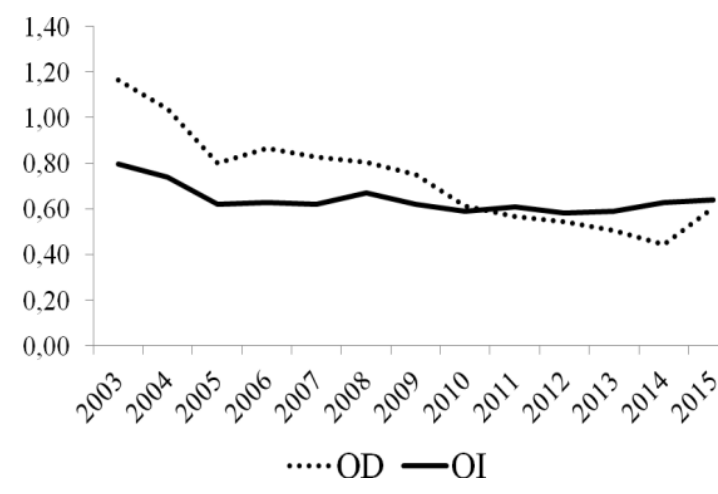

b) Mulher (ocupação) 


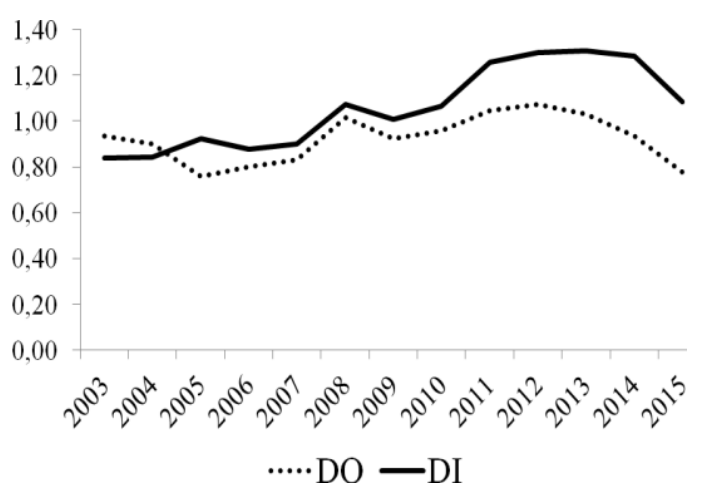

c) Homem (desemprego)

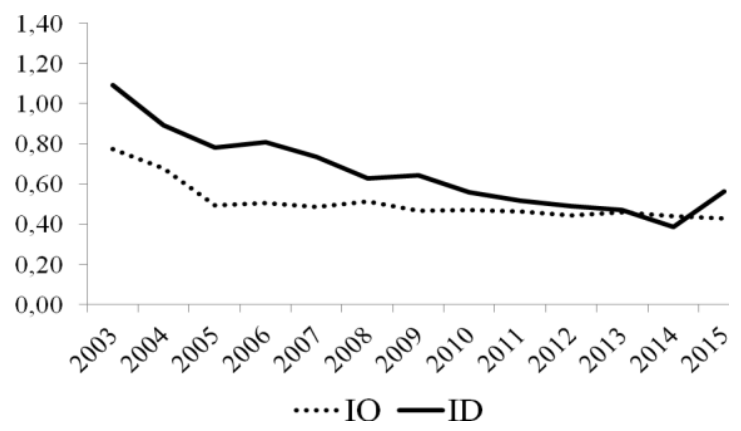

e) Homem (inatividade)

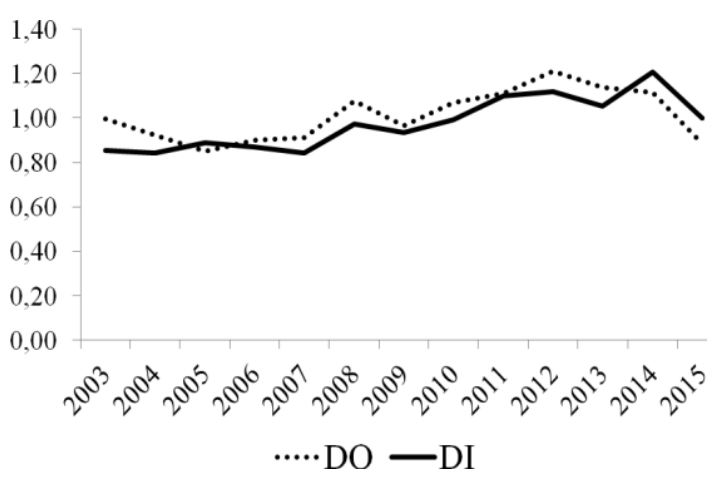

d) Mulher (desemprego)

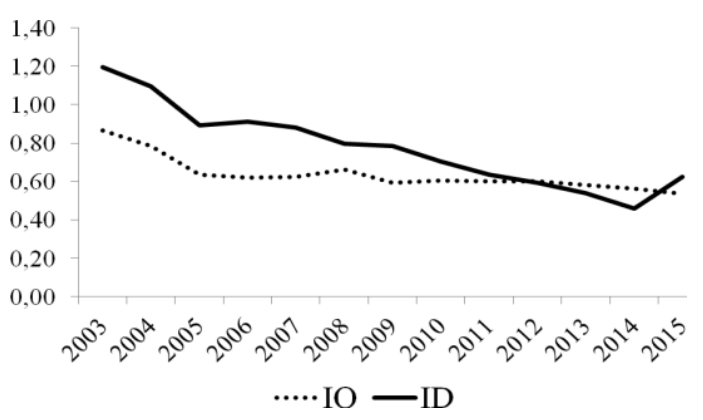

f) Mulher (inatividade)

Fonte: Elaboração própria a partir das informações da PME. Obs.: Modelo estimado utilizando a razão de chances, em que a categoria base é o OO para as estimações OD e OI; DD para as estimações DO e DI e; II para as estimativas de IO e ID.

Ao analisarmos, na Figura 3, os valores correspondentes às estimativas dos parâmetros para o ano de 2015, percebemos redução significativa das chances de transição para a ocupação, a partir tanto da desocupação quanto da inatividade, e, por outro lado, aumento das chances de sair da ocupação para o desemprego e a inatividade. Além disso, os efeitos da crise de 2015 foram maiores para os homens do que para as mulheres, especialmente quando se observam as transições a partir da ocupação para o desemprego e os coeficientes das variáveis binárias de 2014 e 2015, nas Figuras 3a e 3b.

Especificamente para as mulheres, notamos que as chances de as mesmas permanecerem ocupadas são maiores, ou seja, a ida da ocupação para a desocupação ou inatividade diminui, mas que, quando se observa o final da série, é possível perceber um leve aumento evidenciando a crise de 2015 e o fato de que as mulheres estariam tentando complementar a renda domiciliar, dado que a chance da inatividade/desemprego dos homens estava aumentando. 
Assim, a partir dos resultados das estimações foi possível traçarmos um perfil dos ocupados, desocupados e inativos e suas chances de transições no mercado de trabalho brasileiro. Observamos maiores chances para os homens permanecerem ou migrarem para ocupação quando são mais experientes, mais escolarizados, brancos e com filhos menores. Em relação às mulheres, há maiores chances de permanecerem em um posto de trabalho aquelas mais experientes, escolarizadas, brancas, porém sem filhos menores. Fica também evidente o aumento da participação feminina no mercado de trabalho brasileiro, além de que as mesmas são mais "prejudicadas" quando há a presença de filhos de até cinco anos de idade, isso porque elas precisam de jornadas de trabalho mais flexíveis, o que acaba por dificultar a entrada das mesmas na ocupação. De fato, conforme Madalozzo et al. (2010), as mulheres ainda têm maiores dificuldades que os homens na entrada e permanência no mercado de trabalho brasileiro, devido ao fato de sua dupla jornada de trabalho afetar sua produtividade, além de sua saúde e bem-estar. Destacou-se, nas transições a partir da ocupação para o desemprego ou inatividade, o fato de que ser cônjuge, tanto para homens quanto para mulheres, aumenta as chances de migrar para o desemprego e para a inatividade. Verificamos também maiores chances de desocupação para aqueles com mais anos de escolaridade, o que está de acordo com Monte et al. (2011), que constataram maior salário de reserva para os indivíduos mais qualificados.

Por sua vez, com relação aos homens desocupados, os indivíduos que transitam do desemprego para a ocupação são mais experientes e com filhos menores; as mulheres com mais experiência também têm maiores chances de obter um posto de trabalho, contudo sem filhos menores. Em relação às transições do desemprego para a inatividade, podemos salientar o fato de que os homens que possuem filhos de até cinco anos têm menores chances de ir para a inatividade e as mulheres maiores chances de sair do mercado de trabalho. Por sua vez, os homens casados e com filhos menores possuem maiores chances de entrarem no mercado de trabalho a partir da inatividade, quando comparados às mulheres nesta mesma condição.

As estimativas indicaram também que os indivíduos da cor preta, em especial se mulheres, encontram grandes dificuldades de permanecerem empregados ou de encontrarem uma ocupação, ao mesmo tempo em que parecem possuir menores chances de migrarem para a inatividade, provavelmente por uma necessidade premente de obter alguma renda do trabalho. Tais evidências corroboram com Antigo e Machado (2006), que verificaram maior intensidade e fluxo de mulheres na desocupação, e com Menezes e Cunha (2012) que apontam maior duração no desemprego tanto para não brancos quanto para mulheres.

No ano de 2015, quando a crise econômica atinge o país de forma mais intensa, as chances de os indivíduos de ambos os sexos mudarem o status para desocupados passaram a se elevar, com redução na ocupação e aumento da desocupação. Estes resultados estão de acordo com o observado por Nunes et al. (2016), que analisaram o período de 2004 até 2013, em que os movimentos na desocupação se devem mais à redução nas contratações por parte das empresas do que às demissões. Ademais, os efeitos da crise em 2015 foram mais fortes 
Transições no mercado de trabalho brasileiro e os efeitos imediatos da crise econômica dos anos 2010

para os homens, em especial para os da cor preta. Em um ciclo econômico recessivo parecem ser eles os mais assombrados pelo desemprego. Já as mulheres, possivelmente respondendo à necessidade de complementarem a renda familiar, reagiram no início da crise voltando ao mercado de trabalho.

\section{Considerações finais}

No presente trabalho tivemos o objetivo de analisar as transições no mercado de trabalho brasileiro, mais detidamente sua evolução no período de 2002 a 2015, e algumas características do perfil dos indivíduos capazes de influenciarem as chances destas transições, considerando os três estados de referência: ocupação, desocupação e inatividade.

Os resultados apresentados sugerem que o Brasil passou por um longo período de tempo, de 2002 a 2014, no qual se observou ascensão das chances de os indivíduos se manterem no emprego. No movimento da desocupação para a ocupação, notamos maior variabilidade, mas, até o ano de 2014, tal variabilidade não apresentava uma tendência definida, quando passou a ser negativa. Ou seja, a perda de dinamismo da economia brasileira primeiro afetou a capacidade de geração de novas vagas e, posteriormente, a de sustentação dos postos de trabalho existentes.

A inatividade apresentou pequenas oscilações durante o período de análise e se manteve com viés de alta até 2014, quando tem pequena queda parcialmente revertida ao final de 2015. Tal movimento provavelmente refletiu a entrada no mercado de trabalho de cônjuges e filhos tentando compensar a queda na renda familiar, mas que, posteriormente, pela dificuldade de encontrar emprego, se retiram das filas por vagas.

Tanto na fase expansiva quanto na recessiva do mercado de trabalho, o nível de escolaridade do indivíduo parece possuir um papel decisivo nas suas chances de transição ou permanência em um determinado estado. Indivíduos com maior nível de escolaridade possuem mais chances de permanecer no mercado de trabalho, reflexo das suas habilidades que o ajudam a permanecer em seu emprego ou migrar rapidamente para outro posto de trabalho. Da mesma maneira, esses indivíduos têm maiores chances de permanecerem desempregados ou inativos do que migrarem para a ocupação, o que pode ser explicado pelos maiores salários de reserva dos trabalhadores mais qualificados. Deste modo, as estimativas sugerem que os trabalhadores menos qualificados tendem a migrar da inatividade e da desocupação para a ocupação, aceitando mais facilmente postos de trabalho com menor remuneração, dado seu menor salário de reserva e maior custo de oportunidade de permanecerem inativos ou desocupados.

A condição na família mostra que os filhos e os cônjuges tendem a transitar mais de status no mercado de trabalho quando comparados aos chefes de família, uma vez que não são os principais responsáveis pela renda domiciliar, possuindo menor custo de oportunidade de permanecerem desempregados ou inativos. Como esperado, o perfil de transição para trabalhadores com filhos de até 5 anos de idade é diferente para homens e mulheres: enquanto 
os homens possuem maior chance de permanecerem ocupados ou transitarem em direção ao mercado de trabalho, as mulheres tendem a ir para a inatividade ou desemprego, devido ao tempo necessário para cuidar de filhos menores e pela dificuldade de encontrar ocupações capazes de conciliar a dupla jornada de trabalho. Entretanto, merecem maior estudo as razões para os homens com filhos pequenos apresentarem menores chances de sair do emprego e maiores de migrar da desocupação para a ocupação ante aos homens que não ostentam tal condição. Tal evidência sugere que a paternidade de crianças pequenas proporciona ou incentiva os homens a terem maior dedicação em seus trabalhos, o que pode implicar em maior produtividade ou torná-los mais tolerantes às condições de ocupação, fazendo-os, provavelmente, trabalhadores mais atrativos aos empregadores.

As chances de permanência na ocupação e transição para a ocupação mostram diferenças significativas quando considerada a cor dos indivíduos. Trabalhadores de cores preta ou parda possuem menores chances de permanecerem ocupados e transitarem para a ocupação, da mesma forma que possuem maiores chances de permanecerem desocupados no caso específico daqueles da cor preta. Analisando a duração no desemprego este cenário reflete, possivelmente, o comportamento discriminador do mercado de trabalho contra indivíduos deste grupo e, menos provavelmente, características não observáveis que diferenciam as chances de transição.

De qualquer forma, nossas estimativas sugerem evidências de que os indivíduos da raça/cor preta são os mais atingidos em um contexto de crise de emprego, deixando espaço para a discussão da necessidade de se estruturar alguma política pública capaz de atenuar este efeito discriminatório. Como apontado na literatura, o desemprego induz aumento da pobreza e da desigualdade de renda e os diferenciais salariais são importantes determinantes desta desigualdade. Portanto, prevalecendo o viés discriminatório que encontramos nas estimativas, o grupo de indivíduos da cor preta sairá da atual crise mais pobre tanto em termo absoluto quanto relativo.

Em 2015, as condições do mercado de trabalho ainda estavam melhores quando comparadas às observadas no início da série em 2002. No entanto, em relação ao ano de 2015, percebemos a ocorrência de uma diminuição significativa da chance de transições para a ocupação, a partir tanto da desocupação quanto da inatividade, o que reflete o momento de desaquecimento da economia.

De qualquer forma, ao acompanharmos as estatísticas de transição de 2002 a 2015, se evidenciou como as chances de transições reagem às oscilações do ciclo econômico e são afetadas pelas características individuais, fazendo com que determinados grupos sejam mais desfavorecidos nas fases recessivas. Ademais, o prolongamento e aprofundamento da crise econômica em 2016 podem ter conduzido à continuidade da deterioração das condições do mercado de trabalho, tanto em relação à sua capacidade de absorção e retenção de mão de obra quanto à sua qualidade estrutural, com recuo da participação de contratos formais e ascensão de ocupações parciais e precárias, revertendo assim os avanços obtidos no período 
Transições no mercado de trabalho brasileiro e os efeitos imediatos da crise econômica dos anos 2010

de 2002 a 2014. O exame se ocorreu efetivamente este retrocesso e quais os segmentos da população foram mais penalizados merecerá futuras pesquisas.

\section{Referências bibliográficas}

ALVES, J. E. D.; CAVENAGHI, S. A estagnação da taxa de ocupação e o fim precoce do bônus demográfico. In: CONGRESSO DA ASSOCIAÇÃO LATINO-AMERICANA DE POPULAÇÃO, 7; ENCONTRO NACIONAL DE ESTUDOS POPULACIONAIS, 20, Foz do Iguaçu: Alap/Abep, 2016. Anais...

ANTIGO, M. F.; MACHADO, A. F. Transições e duração do desemprego: uma revisão da literatura com novas evidências para Belo Horizonte. Nova Economia, v. 16, n. 3, p. 375-406, set./dez. 2006

BIVAR, W. S. B. Aspectos da estrutura do desemprego no Brasil: composição por sexo e duração. Dissertação (Mestrado)-Departamento de Economia da PUC-RJ, 1993.

BRADBURY, K. Labor market transitions and the availability of unemployment insurance. Federal Reserve Bank of Boston, Jul. 9, 2014. (Working Paper, n. 14-2).

CACCIAMALI, M. C.; LIMA, T. T.; TATEI, F. Determinantes da duração do desemprego no Brasil em crises econômicas. In: CICLO DE DEBATES DA PUC-SP, 11, 2010. Disponível em: http://www.pucsp.br/eitt/downloads/21_12_10/xi-ciclo-de-debates/xi-ciclocacciamali-toledo-tatei.pdf. Acesso em: 11 maio 2016.

CAMARANO, A. A.; KANSO, S. O que estão fazendo os jovens que não estudam, não trabalham e não procuram trabalho? Mercado de Trabalho: Conjuntura e Análise, Rio de Janeiro, IPEA, p. 37-42, nov. 2012.

CAMARGO, J.; REIS, M. Desemprego: o custo da desinformação. Revista Brasileira de Economia, v. 59, n. 3, p. 381-425, 2005.

CAMERON, C.; TRIVEDI, P. K. Microeconometrics: methods and applications. New York: Cambridge University Press, 2005.

CHAHAD, J. P. Z.; POZZO, R. G. Mercado de Trabalho do Brasil na primeira década do século XXI: evolução, mudanças e perspectivas. Ciência \& Trópico, v. 36, p. 100-111, 2012.

CHENG, S.; LONG, J. S. Testing for IIA in the Multinomial Logit Model. Sociological Methods and Research, v. 35, n. 4, p. 583-600, 2007.

CLARK, K. B.; SUMMERS, L. H. Labor market dynamics and unemployment: a reconsideration. Brookings Papers on Economic Activity, v. 1, p. 13-72, 1979.

CLARK, K. B.; SUMMERS, L. H. The dynamics of youth unemployment. In: WISE, David A. (Org). The youth labor market problem: its nature, causes, and consequences. Chicago: University of Chicago Press, 1982. 
Carlos Eduardo Gomes, Renata Lemos Lima, Marina Silva da Cunha, Marcos Roberto Vasconcelos

CUNHA, M. S.; VASCONCELOS, M. R. Evolução da desigualdade na distribuição dos salários no Brasil. Revista Economia Aplicada, v. 16, n. 1, p. 105-136, 2012.

FERNANDES, R.; PAZELLO, E. T.; FELICIO, F. A importância da estrutura familiar e do engajamento no mercado de trabalho na determinação da pobreza no Brasil. Pesquisa e Planejamento Econômico, v. 32, n. 2, p. 233-250, 2002.

FERNANDES, R.; PICCHETTI, P. Uma análise da estrutura do desemprego e da inatividade no Brasil metropolitano. Pesquisa e Planejamento Econômico, v. 29, n. 1, p. 87-112, 1999.

FERREIRA, F.; BARROS, R. P. The slippery slope: explaining the increase in extreme poverty in urban Brazil, 1976-1996. Revista de Econometria, v. 19, n. 2, 1999.

FLORI, P. Desemprego de jovens: um estudo sobre a dinâmica do mercado de trabalho juvenil brasileiro. 2003. Dissertação (Mestrado em Economia)-Faculdade de Economia, Administração e Contabilidade, Universidade de São Paulo, FEA-USP, São Paulo, 2003.

GREENE, W. H. Econometric analysis. 7. ed. New Jersey: Prentice Hall, 2012.

KEYNES, J. M. A teoria geral do emprego, do juro e da moeda. São Paulo: Nova Cultural, 1988. (Os Economistas).

IBGE. PESQUISA MENSAL DE EMPREGO (PME) - 2002-2015. Disponível em: ftp://ftp.ibge.gov.br/Trabalho_e_Rendimento/Pesquisa_Mensal_de_Emprego/Microdados/.

Acesso em: 28 out. 2015.

MADALOZZO, R.; MARTINS, S. R; SHIRATORI; L. Participação no mercado de trabalho e no trabalho doméstico. Estudos Feministas, v. 18, n. 2, p. 547-566, maio/ago. 2010.

MATTOS, F. A. M. de; LIMA, S. da S. Apontamentos para o debate sobre pleno emprego no Brasil. Economia e Sociedade, v. 24. n. 2, (54), p. 293-328, 2015.

MENEZES, A. I.; CUNHA, M. S. Uma análise da duração do desemprego no Brasil (20022011). Revista de Economia de Empresa, v. 13, n. 1, p. 37-58, 2013.

MENEZES-FILHO, N.; PICCHETTI, P. Os determinantes da duração do desemprego em São Paulo. Pesquisa e Planejamento Econômico, v. 30, n. 1, p. 23-48, 2000.

MONTE, P. A. do; RAMALHO, H. M. de B., PEREIRA, M. de L. O salário de reserva e a oferta de trabalho: evidências para o Brasil. Economia Aplicada, v. 15, n. 4, p. 613-639, 2011.

NUNES, D. U.; MENEZES-FILHO, N. A.; KOMATSU, B. K. Probabilidades de admissão e desligamento no mercado de trabalho brasileiro. Estudos Econômicos, São Paulo, v. 46, n. 2, p. 311-341, abr./jun. 2016.

OLIVEIRA, P. R.; SCORZAFAVE, L. G.; PAZELLO, E. T. Desemprego e inatividade nas metrópoles brasileiras: as diferenças entre homens e mulheres. Nova Economia, Belo Horizonte, v. 19, n. 291-324, maio/ago. 2009. 
Transições no mercado de trabalho brasileiro e os efeitos imediatos da crise econômica dos anos 2010

PEUTERE, L.; VAHTERA, J.; KIVIMÄKI, M.; PENTTI, J.; VIRTANEN, P. Job contract at birth of the first child as a predictor of women's labor market attachment: trajectory analyses over 11 years. Nordic Journal of Working Life Studies, v. 5, n. 1, Mar. 2015.

RIBAS, R. P.; SOARES, S. S. D. Sobre o painel da Pesquisa Mensal do Emprego (PME) do IBGE. Brasília: Ipea, 2008. (Texto para Discussão, n. 1.348).

SILVA, F. J. F.; PIRES, L. S. Evolução do desemprego no Brasil no período 2003-2013: análise através das probabilidades de transição. Brasília: Banco Central do Brasil, fev. 2014. 32p. (Trabalho para Discussão, n. 349).

SCORZAFAVE, L. G.; MENEZES-FILHO, N. Participação feminina no mercado de trabalho brasileiro: evolução e determinantes. Pesquisa e Planejamento Econômico, v. 31, n. 3, p. 441-478, 2001.

SMALL, K. A.; HSIAO, C. Multinomial logit specification tests. International Economic Review, v. 26, n. 3, p. 619-627, 1985.

SOARES, S. S. D. O perfil da discriminação no mercado de trabalho - homens negros, mulheres brancas e mulheres negras. Brasília: Instituto de Pesquisa Econômica Aplicada, 2000. (Texto para Discussão, n. 769).

SQUEFF, G. C.; DE NEGRI, F. Produtividade do trabalho e mudança estrutural no Brasil nos anos 2000. In: DE NEGRI, Fernanda; CAVALCANTE, Luiz R. (Org.). Produtividade no Brasil: desempenho e determinantes (v.1 - Desempenho). Brasília: Instituto de Pesquisa Econômica Aplicada, 2014.

STIERA, H.; ENDEWELDA, M. Employment transitions and labor market exits: age and gender in the Israeli labor market. Research in Social Stratification and Mobility, v. 41, p. 93-103, Sept., 2015.

VENTURI, G.; TORINI, D. Transições da escola para o mercado de trabalho de mulheres $e$ homens jovens no Brasil. Genebra: Organização Mundial do Trabalho, 2014. (Work4Youth, n. 25).

WARD-WARMEDINGER, M.; MACCHIARELLI, C. Transitions in labour market status in the European Union. LSE 'Europe in Question’ Nov. 2013. (Discussion Paper Series, LEQS Paper, n. 69), 